\title{
Juntos na costa: zooarqueologia e geoarqueologia de sambaquis do litoral sul catarinense
}

\author{
Daniela Klokler* \\ Ximena S. Villagrán** \\ Paulo C.F. Giannini** \\ Silvia Peixoto* \\ Paulo DeBlasis ** *
}

\begin{abstract}
KLOKLER, D.; VILLAGRÁN, X.S.; GIANNINI, P.C.F.; PEIXOTO, S.; DEBLASIS, P.
Juntos na costa: zooarqueologia e geoarqueologia de sambaquis do litoral sul catarinense. Revista do Museu de Arqueologia e Etnologia, São Paulo, 20: 53-75, 2010.
\end{abstract}

Resumo: Neste artigo, explora-se a contribuição que análises zooarqueológicas e geoarqueológicas podem fornecer ao entendimento da sucessão deposicional de sambaquis. Esta abordagem combinada é aplicada ao estudo de dois sambaquis que representam parte da diversidade dos sitios da costa sul de Santa Catarina: Jabuticabeira II, sambaqui-cemitério, cujas pesquisas tiveram papel decisivo para uma compreensão mais detida do ritual funerário; e Encantada III, um sambaqui pequeno que, apesar de sua aparente simplicidade, apresenta um desafio para a definição de sua função. Em Encantada III, tanto a Zooarqueologia como a Geoarqueologia contribuiram para uma melhor caracterização do seu papel enquanto depósito resultante de atividades de curto prazo, porém, de permanência duradoura. Ambos os sambaquis, bem como suas atribuições práticas e simbólicas, são exemplos da complexa dinâmica envolvida na construção antrópica da paisagem.

Palavras-chave: Sambaquis - Arqueologia costeira - Zooarqueologia Geoarqueologia - Micromorfologia.

$\mathrm{O}$ sambaquis são a evidência mais conspicua e recorrente das populações pré-históricas que habitaram a maior parte da costa brasileira. Após o debate no século XIX acerca da artificialidade dessas estruturas, visão

(*) Museu Nacional da Universidade Federal do Rio de Janeiro. <dklokler@email.arizona.edu>, <silviapeixoto@gmail.com> $\left.{ }^{* *}\right)$ Instituto de Geociências da Universidade de São Paulo.<villagran@usp.br>, <pcgianni@usp.br> $\left.{ }^{(* * *}\right)$ Museu de Arqueologia e Etnologia da Universidade de São Paulo. <deblasis@usp.br> que acabou prevalecendo no começo do século seguinte, as preocupações sobre as origens dos sitios deram lugar a um enfoque largamente direcionado à dieta ou à saúde dos seus construtores. Até meados de 1990, a maior parte da literatura referia-se aos construtores de sambaquis como pequenos grupos nômades que percorriam a costa em busca de bancos de moluscos, os quais - após certo periodo de tempo - desenvolveram a pesca como estratégia de subsistência (Beck 1972; Emperaire e Laming 1956a e b; Garcia e Uchoa 1981; Lima 1991). 
A visão das populações costeiras como organizações sociais simples que possuiam uma economia baseada na exploração de um único recurso natural - moluscos ao longo de grande parte de sua existência, e depois peixes quando os bancos de moluscos foram supostamente exauridos devido à superexploração - mudou com a influência da Arqueologia Processual no Brasil. Estimativas sobre o retorno energético do consumo de moluscos mostraram que a coleta é uma atividade de baixo benefício indicando a baixa probabilidade de sociedades caçadoras-coletoras terem baseado suas economias apenas no consumo de moluscos (Figuti e Klökler 1996; Klökler 2001; Meehan 1982.

Com a incorporação de cálculos de quantidade de carne a partir de ossos e conchas, essas populações costeiras começaram a ser consideradas como principalmente pesqueiras e altamente adaptadas à exploração dos recursos do ecossistema que habitavam, que incluia uma grande variedade de espécies de peixes, moluscos e gastrópodes (Figuti 1992, 1993). Sob essa perspectiva, os sambaquis passaram a ser encarados como estruturas intencionalmente construídas, e não locais resultantes do acúmulo aleatório de restos alimentares. Sambaquis são definidos como espaços sagrados e mundanos, nos quais tanto atividades rituais como cotidianas eram desempenhadas e associação entre contextos funerários e acumulação de vestigios ósseos e malacológicos uma caracteristica intrinseca da sociedade sambaquieira (Gaspar 1994/1995). Atualmente, as populações que construiram os sambaquis são consideradas como organizações complexas e estáveis (DeBlasis et al. 1998, 2007; Fish et al. 2000; Gaspar 1998, 2000). Os locais escolhidos para assentamento destacam-se pela sua riqueza de recursos, com fácil acesso ao mar, lagoas, estuários, mangues e florestas, o que permitia a essas comunidades pescar, coletar, caçar e, provavelmente, praticar uma forma incipiente de horticultura (Gaspar e Klökler 2003; ScheelYbert et al. 2003).

No estado de Santa Catarina, onde a ocupação costeira iniciou-se há aproximadamente 7.000 anos AP (DeBlasis et al. 2007), os sambaquis são conhecidos por sua dimensão monumental e grande visibilidade na paisagem. O projeto multidisciplinar Sambaquis e Paisagem, que concentrou seus estudos na costa meridional do estado, chamou atenção para a possibilidade de alguns desses sambaquis terem tido a função exclusiva de cemitério (Fish et al. 2000). Na área piloto desse Projeto, dominada por um sistema lagunar que evoluiu a partir de uma grande paleobaia (Giannini 1993; Giannini et al. 2010), mais de 70 sambaquis já foram identificados. Pesquisas detalhadas foram realizadas, especialmente em dois sítios Jabuticabeira II e Encantada III (Fig. 1).

Jabuticabeira II foi submetido a várias intervenções arqueológicas, sendo um dos sitios mais estudados da área (ver Bianchini et al. 2007; Boyadjian 2007; DeBlasis et al. 1998, 2007; Fillipini e Eggers 2005-2006; Fish et al. 2000; Gaspar et al. 2008; Klökler 2001, 2008; Nishida 2007; Okumura e Eggers 2005; Storto et al. 1999; Villagran 2008; Villagran et al. 2009, entre outros). Os resultados obtidos a partir de estratégias combinadas de amostragem para zooarqueologia e paleobotânica nesse sambaqui (Scheel-Ybert et al. 2005-2006), motivaram o desenvolvimento de abordagens de campo e laboratório que integrassem estudos zooarqueológicos com análises geoarqueológicas e que pudessem ser implementadas em outros sítios independentemente de localização ou tamanho. Neste artigo, apresentam-se os métodos aplicados e resultados obtidos em Jabuticabeira II, onde a abordagem integrada revelou a cadeia de atividades envolvida na construção desse sítio; e em Encantada III, exemplo de um tipo de sítio menos conspícuo $\mathrm{e}$, consequentemente, menos estudado.

\section{Implementação das análises}

\section{Jabuticabeira II}

O sitio Jabuticabeira II possui aproximadamente $320.000 \mathrm{~m}^{3}$ de volume e altura máxima de 9 metros. Encontra-se parcialmente assentado sobre depósitos eólicos datados do prémáximo de transgressão holocênico (Giannini 1993; Giannini et al. 2007; Rodrigues 2009). 
Daniela Klokler

Ximena S. Villagrán

Paulo C.F. Giannini

Silvia Peixoto

Paulo DeBlasis
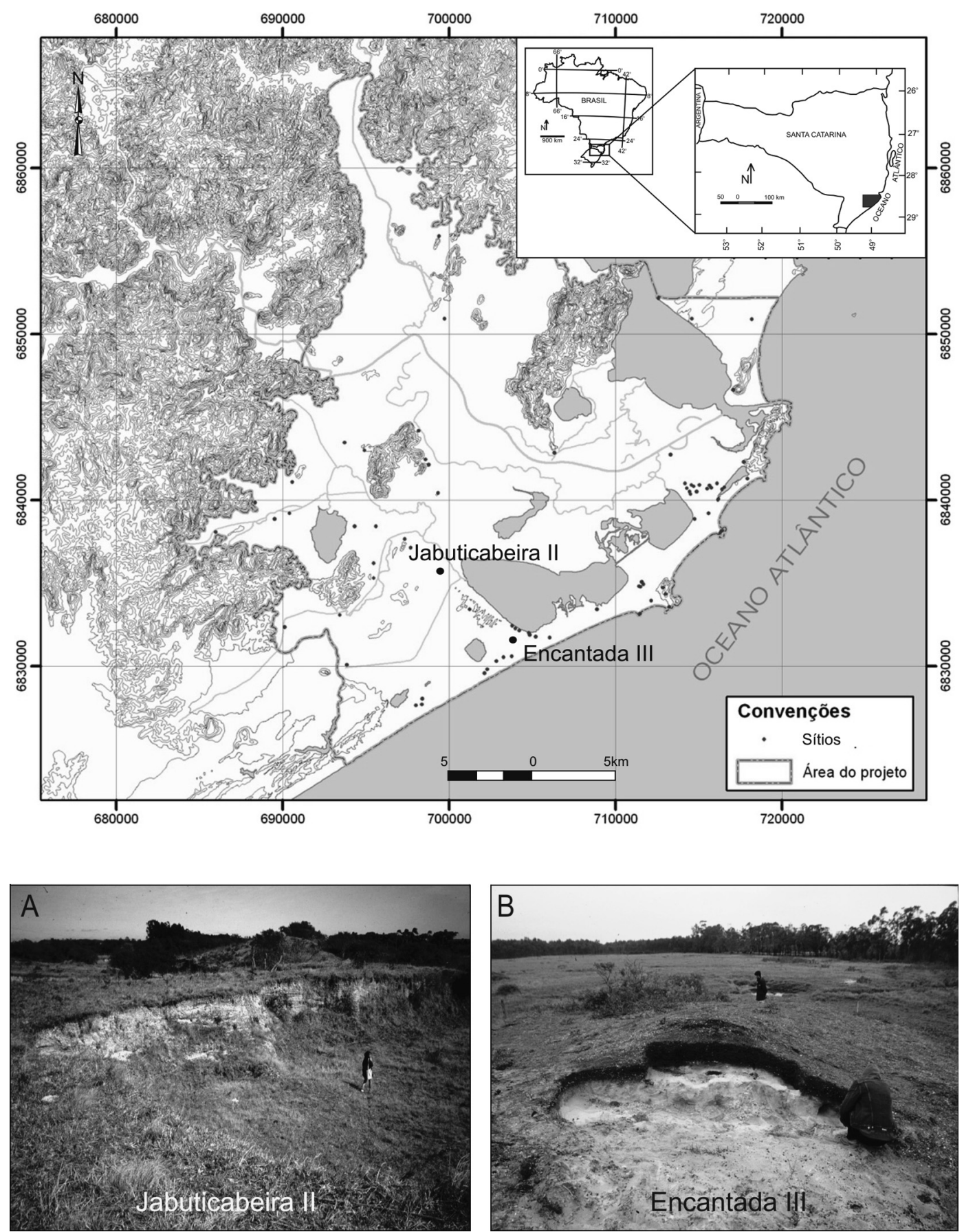

Fig. 1. Área de estudo na costa meridional do estado de Santa Catarina com a localização e fotografias dos sambaquis de Jabuticabeira II (A) e Encantada III (B). Mapa de autoria de Rafael Brandi, fotografias de Paulo C.F. Giannini.

Ele é composto de dois depósitos estratificados principais: um de conchas na parte inferior, datado em $2880 \pm 75$ (DeBlasis et al. 2007)

(Fig. 1A), e um depósito preto, composto 
principalmente de ossos de peixe, queconstitui a parte superior de quase todo o sítio. Portanto, Jabuticabeira II é essencialmente um sambaqui composto por um depósito conchífero coberto por um depósito ictiológico (ou ictio-montículo). A construção do ictio-monticulo iniciou-se a partir de aproximadamente $1.700 \mathrm{AP}$ e continuou até $\mathrm{o}$ abandono do sítio, em torno de $1180 \pm 40$ anos AP (Villagran et al. 2009; Villagran et al. 2010).

Uma caracteristica notável do depósito conchifero é a combinação sucessiva de camadas espessas (entre $10 \mathrm{~cm}$ e $1 \mathrm{~m}$ de espessura), compostas de conchas soltas e areia que formam montículos, e camadas centimétricas escuras (de coloração preta a castanho-escura e cinza escura) compostas de ossos de peixes, carvão e material orgânico fino. As camadas de conchas geralmente não possuem estruturas internas ou artefatos, ao passo que as camadas escuras contêm numerosos sepultamentos, fogueiras e buracos de estaca, além de artefatos líticos e ósseos (Fig. 2A). Foram identificadas relações espaciais e temporais entre os componentes das camadas escuras, o que levou à sua associação com atividades funerárias (99\% dos sepultamentos em Jabuticabeira II se encontram nestas camadas) (Fish et al. 2000; Karl 2000). Assim, essas camadas foram denominadas "áreas funerárias", que correspondem a locais especificos de sepultamento de individuos pertencentes a grupos de afinidade. O termo "grupo de afinidade" foi proposto por Gaspar (DeBlasis et al. 2004) e define unidades sociais negociadas através de ligações clânicas, politicas, econômicas etc.. No íctio-montículo, nota-se um arranjo semelhante de camadas, mas sem a presença de camadas de conchas, que são substituídas pela presença massiva de restos de peixe. A mudança abrupta na composição levou à hipótese de descontinuidade funcional (Gaspar 1998), possivelmente relacionada à chegada à costa de grupos do interior, que teria motivado alterações dentro do sistema social dos construtores de sambaquis.

\section{Análise faunística do sambaqui}

Uma vez que a matriz do sítio é composta basicamente de restos faunísticos (valvas de moluscos e ossos de peixes), considerou-se apropriada a utilização de uma abordagem zooarqueológica para compreender a sua história deposicional. Assim, o primeiro objetivo das análises faunisticas foi compreender a formação do sítio, ao invés de privilegiar o estudo da subsistência do grupo construtor. As pesquisas zooarqueológicas em Jabuticabeira II incluiram tanto amostras de colunas retiradas em perfis quanto de escavação. A amostragem de colunas foi selecionada como estratégia de coleta ao permitir verificar mudanças verticais/ temporais na deposição das camadas. Todas as amostras tiveram um volume padronizado de 1,5 l, com exceção de estruturas especificas (covas rasas, buracos de estaca, fogueiras), que por vezes não possuiam material suficiente para completar o volume necessário. Esta estratégia de amostragem evita a seleção em campo de elementos ou fragmentos pertencentes a espécies conhecidas, exemplares maiores ou melhor preservados, bem como vieses resultantes da experiência do pesquisador na identificação de materiais faunísticos.

Sete colunas de amostragem foram realizadas em três locais diferentes do sítio, tanto na sua periferia como na área central. Seis colunas foram coletadas no depósito conchifero e uma coluna adveio do íctio-montículo. Durante a escavação de uma área funerária, foram coletadas amostras de covas rasas, buracos de estaca e fogueiras.

Camadas soltas, espessas e de coloração clara (branco a cinza claro), que dominam a maior parte da estratigrafia do sítio, estão compostas principalmente por conchas inteiras (algumas delas articuladas e fechadas) de Anomalocardia brasiliana, ou berbigão, além de areia (Klökler 2001). Outros tipos de moluscos, tais como mexilhões, mariscos e gastrópodes diversos (Tabela 1), também estão presentes embora com frequências menores, atingindo no máximo 30\% da composição das camadas. As valvas não exibem evidências de abertura ou quebra intencional, e apenas um pequeno percentual - $2.5 \%$ em média - exibe sinais de queima. As camadas conchiferas também contêm vestigios de espécies de peixes locais, tais como: corvina (Micropogonias furnieri), bagre 
(Genidens sp), miraguaia (Pogonias cromis), sargode-dente (Archosargos probatocephalus), sendo que todas as espécies identificadas poderiam ser capturadas facilmente na laguna. As caracteristi- cas das camadas indicam que as mesmas não resultam de um único episódio de deposição, mas de várias deposições sucessivas no tempo, sem um grande hiato temporal entre uma e outra.

Tabela 1

\begin{tabular}{|c|c|c|c|c|}
\hline \multicolumn{5}{|c|}{ Material epigráfico del área I: } \\
\hline & $\begin{array}{c}\text { Nome } \\
\text { científico }\end{array}$ & $\begin{array}{l}\text { Nome } \\
\text { popular }\end{array}$ & $\begin{array}{c}\text { Jabuticabeira } \\
\text { II }\end{array}$ & $\begin{array}{c}\text { Encantada } \\
\text { III } \\
\end{array}$ \\
\hline \multirow[t]{17}{*}{ Peixe } & Archosargus probatocephalus & Sargo-de-dente & $\mathrm{x}$ & \\
\hline & Cynoscion acoupa & Pescada acoupa & $\mathrm{x}$ & \\
\hline & Cynoscion leiarchus & Pescada-branca & $\mathrm{x}$ & \\
\hline & Larimus breviceps & Oveva & $\mathrm{x}$ & \\
\hline & Pogonias cromis & Miraguaia & $\mathrm{x}$ & \\
\hline & Microponias furnieri & Corvina & $\mathrm{x}$ & $\mathrm{x}$ \\
\hline & $\begin{array}{l}\text { Ariidae (Genidens barbus e } \\
\text { Genidens genidens) }\end{array}$ & Bagre branco e bagre guri & $\mathrm{x}$ & $\mathrm{x}$ \\
\hline & Mugil sp. & Tainha & $\mathrm{x}$ & $\mathrm{x}$ \\
\hline & Pomatomus saltatrix & Anchova; enchova & $\mathrm{x}$ & \\
\hline & Conodon nobilis & Roncador & $\mathrm{x}$ & \\
\hline & Haemulidae & Roncador & $\mathrm{x}$ & $\mathrm{x}$ \\
\hline & Lagocephalus laevigatus & Baiacú-ará & $\mathrm{x}$ & \\
\hline & Oligoplites sp. & Guaivira; salteira & $\mathrm{x}$ & \\
\hline & Centropomus sp. & Robalo & $\mathrm{x}$ & \\
\hline & Rhinoptera bonasus & Raia & $\mathrm{x}$ & \\
\hline & Selachimorpha sp. & Tubarão & $\mathrm{x}$ & \\
\hline & Chaetodipterus faber & Parú & $\mathrm{x}$ & \\
\hline \multirow[t]{13}{*}{ Moluscos } & Anomalocardia brasiliana & Berbigão & $\mathrm{x}$ & $\mathrm{x}$ \\
\hline & Tagelus plebeius & Dedo de moça & $\mathrm{x}$ & $\mathrm{x}$ \\
\hline & Donax hanleyanus & Moçambique & $\mathrm{x}$ & $\mathrm{x}$ \\
\hline & Lucina pectinata & Ameijoa; lambreta & $\mathrm{x}$ & $\mathrm{x}$ \\
\hline & Ostrea sp. e Crassostrea sp. & Ostras & $\mathrm{x}$ & $\mathrm{x}$ \\
\hline & Erodona mactroides & & $\mathrm{x}$ & \\
\hline & Macoma constricta & & $\mathrm{x}$ & \\
\hline & Nassarius vibex & & $\mathrm{x}$ & $\mathrm{x}$ \\
\hline & Neritina virginea & & $\mathrm{x}$ & \\
\hline & Brachidontes sp. & Mexilhão dos tolos & $\mathrm{x}$ & $\mathrm{x}$ \\
\hline & Cyrtopleura costata & Asa de anjo & $\mathrm{x}$ & $\mathrm{x}$ \\
\hline & Crepidula sp. & & $\mathrm{x}$ & \\
\hline & Thais haemastoma & Sacuritá, caramujo- liso & $\mathrm{x}$ & $\mathrm{x}$ \\
\hline Crustáceos & Calinectes sp. & Siri & $\mathrm{x}$ & $\mathrm{x}$ \\
\hline \multirow[t]{3}{*}{ Aves } & Ardeidae & Socó, garça & $\mathrm{x}$ & \\
\hline & Spheniscus magellanicus & Pinguim-de-magalhães & $\mathrm{x}$ & \\
\hline & Aves indeterminadas & & $\mathrm{x}$ & $\mathrm{x}$ \\
\hline Equinodermos & Encope emarginata & Bolacha-do-mar & $\mathrm{x}$ & $\mathrm{x}$ \\
\hline \multirow[t]{2}{*}{ Mamíferos } & Hydrochoerus hydrochaeris & Capivara & $\mathrm{x}$ & \\
\hline & Tapirus terrestris & Anta & $\mathrm{x}$ & \\
\hline
\end{tabular}


Tabela 1 (Cont.)

\begin{tabular}{|c|c|c|c|c|}
\hline \multicolumn{5}{|c|}{ Material epigráfico del área I: } \\
\hline & $\begin{array}{l}\text { Nome } \\
\text { científico }\end{array}$ & $\begin{array}{l}\text { Nome } \\
\text { popular }\end{array}$ & $\begin{array}{c}\text { Jabuticabeira } \\
\text { II }\end{array}$ & $\begin{array}{c}\text { Encantada } \\
\text { III }\end{array}$ \\
\hline \multirow[t]{9}{*}{ Mamíferos } & Tapirus terrestris & & $\mathrm{x}$ & \\
\hline & Tayassu sp. & Porco-do-mato & $\mathrm{x}$ & \\
\hline & Mazama sp. & Veado & $\mathrm{x}$ & \\
\hline & Dasypus novemcinctus e & Tatu-galinha e tatu-peba & $\mathrm{x}$ & \\
\hline & Euphractus sexcinctus & Bugio & $\mathrm{x}$ & \\
\hline & Alouatta sp. & Paca & $\mathrm{x}$ & \\
\hline & Agouti paca & Porco-espinho & $\mathrm{x}$ & \\
\hline & Erethizontidae & & & \\
\hline & Mamiferos indeterminados & & & $\mathrm{x}$ \\
\hline \multirow[t]{3}{*}{ Répteis } & Chelidae & Tartaruga & $\mathrm{x}$ & \\
\hline & Caiman latirostris & Jacaré-de-papo-amarelo & $\mathrm{x}$ & \\
\hline & Répteis indeterminados & & $\mathrm{x}$ & $\mathrm{x}$ \\
\hline
\end{tabular}

As camadas centimétricas de coloração escura possuem, no geral, baixa quantidade de conchas Berbigões e mariscos representam cerca de $15 \%$ do total. Parte dos moluscos (53\%) exibe sinais de intemperismo, tais como coloração amarronzada ou avermelhada, e indícios de dissolução de carbonato de cálcio, assim como evidências de queima. Alteração térmica foi igualmente observada nos ossos de peixe que, além de exibirem vários graus de queima, apresentam-se em frequências mais altas nas camadas escuras que nas camadas de conchas, o que sugere um processamento diferenciado desses vestígios (Fig. 2B). Ossos e otólitos também apresentam-se altamente intemperizados (Klökler 2008, Nishida 2007) em muitos casos dificultando sua identificação.

A análise das estruturas (covas, buracos de estaca e fogueiras) mostrou que a sua composição se assemelha muito às características das camadas escuras, com pequenas diferenças como maior grau de queima nos materiais recuperados das fogueiras e presença de animais exóticos nas covas (considerados oferendas), o que indica que as estruturas foram escavadas dentro da matriz de lentes escuras, não afetando as camadas de conchas abaixo. Cabe lembrar que apesar do uso do termo "cova", os enterramentos em Jabuticabeira II foram realizados em pequenas depressões, com tamanho suficiente para acomodar o corpo, ou seja, com concavidade mínima.
Análises de fragmentação foram realizadas para verificar possiveis áreas de pisoteamento. Os resultados não indicaram espaços com diferenças significativas de fragmentação, mas permitiram verificar uma distinção entre as camadas conchiferas e escuras. As camadas conchiferas possuem ocorrência escassa de valvas de moluscos quebradas, em oposição às camadas escuras que, em geral, apresentam maior compactação e material fragmentado (Klökler 2001). Além disso, as camadas escuras incluem todas as estruturas encontradas no sítio. Estes resultados podem ser interpretados como possiveis indicadores de pisoteamento, sem que, contudo, tenham afetado as camadas conchiferas subjacentes. Sugere-se, portanto, que a preparação e organização das atividades associadas à deposição das camadas escuras ocorriam em área próxima ou adjacente ao sítio.

Como mencionado anteriormente, a ausência de artefatos fora dos contextos funerários, bem como de áreas para o preparo diário de comida, assim como a recorrente presença de estruturas associadas aos sepultamentos, como fogueiras e buracos de estaca, são indícios da função eminentemente funerária do sítio. Neste sentido, a grande quantidade de ossos de peixe entre os quais eram sepultados os membros da comunidade (Klökler2001) poderia corresponder aos remanescentes de 
festins funerários realizados em homenagem aos mortos. As camadas de conchas representariam episódios de coleta e transporte de quantidades imensas de conchas de moluscos, em particular de uma espécie especifica: berbigão, para cobrir as áreas funerárias e outorgar volume à estrutura. A. brasiliana é um pequeno molusco (raramente maior que $4 \mathrm{~cm}$ ) bastante comum, que ocorre nos estuários da região e pode ser recolhido facilmente em grandes quantidades. As conchas teriam sido usadas para cobrir covas individuais ou uma série delas, ao mesmo tempo em que aumentavam o tamanho do sitio horizontal e verticalmente.

Para articular as atividades envolvidas na configuração das camadas escuras a fim de compreender o ritual funerário dos construtores desse sambaqui, a segunda fase da análise zooarqueológica teve por intuito compreender os comportamentos que originaram os dois conjuntos de camadas, com ênfase nas características das camadas escuras, que permitiriam interpretar a natureza e a escala dos festins, verificar possiveis diferenças entre os eventos e complementar a análise dos processos de formação (Klökler2008).

O objetivo foi comparar os itens servidos durante os banquetes e suas quantidades, investigando a possibilidade de que grupos tivessem acesso desigual aos recursos e/ou às preferências alimentares para o ritual. Além disso, a investigação de diferenças no que concerne à escala dos eventos poderia indicar maiores investimentos no banquete em função do status ou do número de participantes. Amostras de onze áreas funerárias foram analisadas, além de materiais de preenchimento de covas, buracos de estaca e fogueiras. Nesta etapa, o volume recuperado foi de 8 litros de material por amostra.

As espécies de peixe mais comuns encontradas foram: bagre (Genidens sp), corvina (Micropogonias furnieri), sargo de dente (Archosargus probatocephalus), miraguaia (Pogonias cromis) e tainha (Mugil sp). Juntos, bagres e corvinas representam 70\% dos restos de peixe recuperados. As medições dos otólitos dessas duas espécies demonstraram que a maioria dos espécimes é jovem, a faixa etária mais comum encontrada nos estuários. Os resultados demonstram que a maior parte da pesca era empreendida na laguna vizinha, com o uso de redes (Klökler 2008). As espécies em todas as áreas funerárias são geralmente as mesmas e possuem frequências similares. Isto sugere que grupos de afinidade distintos tinham acesso a áreas de pesca semelhantes.

Cálculos para estimar a biomassa de peixes e moluscos foram realizados utilizando valores introduzidos por Figuti (1992, 1993), respectivamente 20 e .34 , para determinação de quantidades de carne em relação aos ossos e conchas. Estimativas indicam que peixes foram a mais importante fonte de alimento, tanto nas camadas de cobertura quanto nas áreas funerárias, não obstante a grande diferença nas quantidades de valvas de moluscos. As áreas funerárias estudadas possuem uma média de $281 \mathrm{~kg}$ de carne de peixe disponivel por metro cúbico. Este valor representa uma quantidade de comida tal que poderia ter sido usada em eventos com um número elevado de participantes (Fig. 2C). No ictio-monticulo, os mesmos padrões observados para a fauna ictiológica na camada conchifera são verificados, o que sugere a utilização das mesmas áreas e técnicas de pesca ao longo de todo o periodo de construção de Jabuticabeira II. Em termos especificos, três áreas funerárias exibem quantidades notáveis de restos de ossos de peixe, o que foi interpretado como três grupos com festins mais abastados, ou seja, com um montante de peixe maior à disposição dos convidados.

\section{Geoarqueologia do íctio-montículo}

Com o intuito de explorar a dinâmica construtiva associada à formação do ictiomontículo, duas trincheiras (10 e 11) foram abertas na área onde este depósito alcança $2 \mathrm{~m}$ de altura. Perfis estratigráficos das trincheiras foram descritos de acordo com identificação de fácies arqueológicas (ver Villagran 2008 e Villagran et al. 2009 ) (Fig. 3). Recolheram-se 


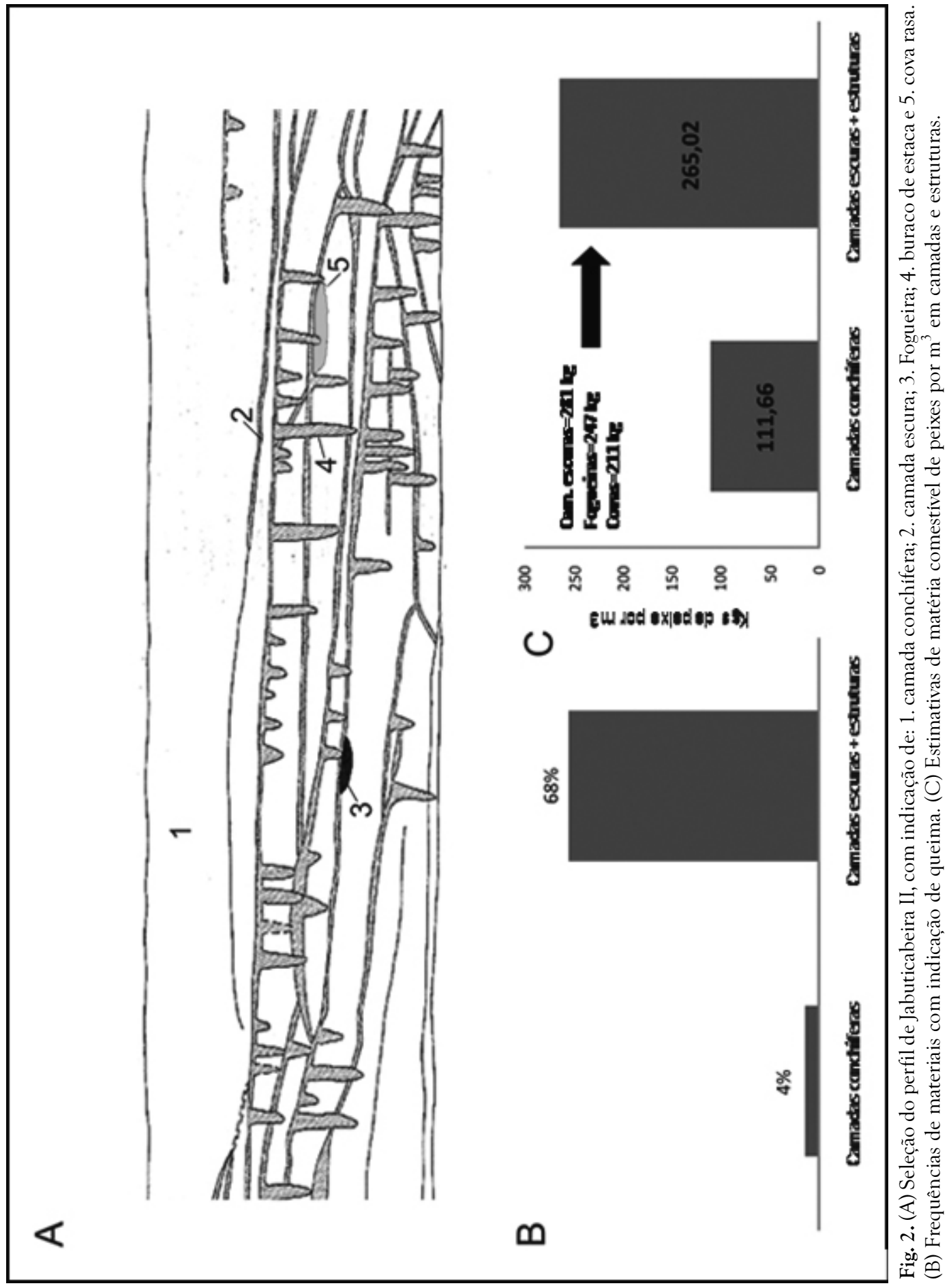


amostras de todas as fácies para determinação das suas propriedades fisicas, químicas, mineralógicas e micromorfológicas. Sete sondagens externas foram abertas fora do sítio - nas partes adjacentes a este, para fins de comparação dos sedimentos geogênicos com os antropogênicos. Amostras de sedimento total foram coletadas do horizonte superior (horizonte A) de cada sondagem externa.

A composição mineralógica da fração argila foi determinada por difractometria de raios-x (DRX) com difractômetro Siemens D500. Amostras inalteradas foram coletadas nas trincheiras 10 e 11 , secadas em estufa e impregnadas sob vácuo com uma mistura de resina epóxi, catalisador e acetona, de acordo com de Paula et al. (1991). Seções finas foram analisadas sob o estereomicroscópio e microscópio ótico em luz polarizada plana (PPL) e luz polarizada cruzada (XPL), em aumentos de 2.5 x a 40 x. A descrição seguiu as diretrizes de Bullock et al. (1985), Courty et al. (1989), Fitzpatrick (1993) e Stoops (2003). Análises de microscopia eletrônica de varredura (MEV), com espectrometria de energia dispersiva (sistema MEV-EED) foram realizadas em seções finas recobertas com ouro e/ou carbono.

As sondagens externas ao sitio mostraram uma sucessão de fácies arenosas, amarelo claro, sob uma fácies de lama arenosa preta. Esta sucessão foi interpretada como fácies de margem paleolagunar, de praia e brejo, respectivamente (Fig 5). A avaliação macroscópica das trincheiras analisadas (10 e 11) demonstrou que o ictio-montículo é formado por uma sucessão de unidades arqueológicas com estrutura granular, limites abruptos (menos de $2 \mathrm{~cm}$ de espessura), compostas de fragmentos de ossos de peixes não selecionados e areia terrigena de granulometria fina a muito fina. Fragmentos de carvão também são observados, e a sua proporção varia de acordo com as diferentes unidades. Apesar da complexidade da sua composição, a geometria monticular descrita para o depósito malacológico também pode ser observada no ictio-montículo (Villagran et al. 2009; Villagran et al. 2010).

A análise química multi-elementar mostrou que a estratigrafia complexa do ictio-montículo pode ser simplificada em sete fácies arqueológicas (Fig. 3), três das quais representam episódios discretos, porém recorrentes, de deposição na construção do depósito (Villagran et al. 2009). Estas são: unidade superior de ambas as trincheiras, de coloração marrom escuro (10YR $3 / 2$ ), mais compactada e com elementos intrusivos modernos, tais como tijolos e plástico (fácies 1); unidades centimétricas pretas (10YR 2/1) compostas de carvão e fragmentos de ossos queimados (10-15\%) (fácies 2); unidades decimétricas de coloração marrom (10YR 4/2) com ossos de peixes fragmentados e intemperizados (10-30\%) (fácies 3); camadas centimétricas de coloração cinza (10YR 3/1) compostas de carvão, cinzas e ossos queimados (10-15\%) (fácies 4); camadas decimétricas de coloração marrom claro (10YR 4/2) com ossos de peixes muito fragmentados (30-50\%), queimados e intemperizados, com lentes de areia e cinzas (fácies 5); fogueira in situ (fácies 6); e lâmina de areia solta (10YR 6/2) (fácies 7). A porosidade e fragilidade aumentam próximo à base das trincheiras, bem como a frequência de cinzas.

A análise microscópica corroborou o fato de as unidades se diferenciarem apenas na frequência de fragmentos de ossos queimados e na composição da fração fina que os acompanha (Villagran et al. 2009; Villagran et al. 2010). Sob polarizadores cruzados (XPL), a maioria dos fragmentos de ossos mostra baixa birrefringência, o que indica a deterioração do colágeno (Schoeninger et al. 1989), por dissolução ou como resultado da queima. A alteração tanto da fração orgânica, quanto da fração mineral dos ossos observada da base ao topo dos perfis, indica periodos de exposição intempérica (Trueman et al. 2004). A alta porosidade do depósito, chuvas sazonais, atividade microbiana e liberação de ácidos pela decomposição de matéria orgânica teriam favorecido o processo de alteração após o enterramento.

Além dos fragmentos de ossos distribuidos aleatoriamente (30-50 \%), a fração grossa é dominada por grãos de quartzo (15-30 \%) e fragmentos de carvão (5-10 \%). Apenas os grãos de quartzo são arredondados e bem selecionados (100-200 im). Sua possivel origem foi 


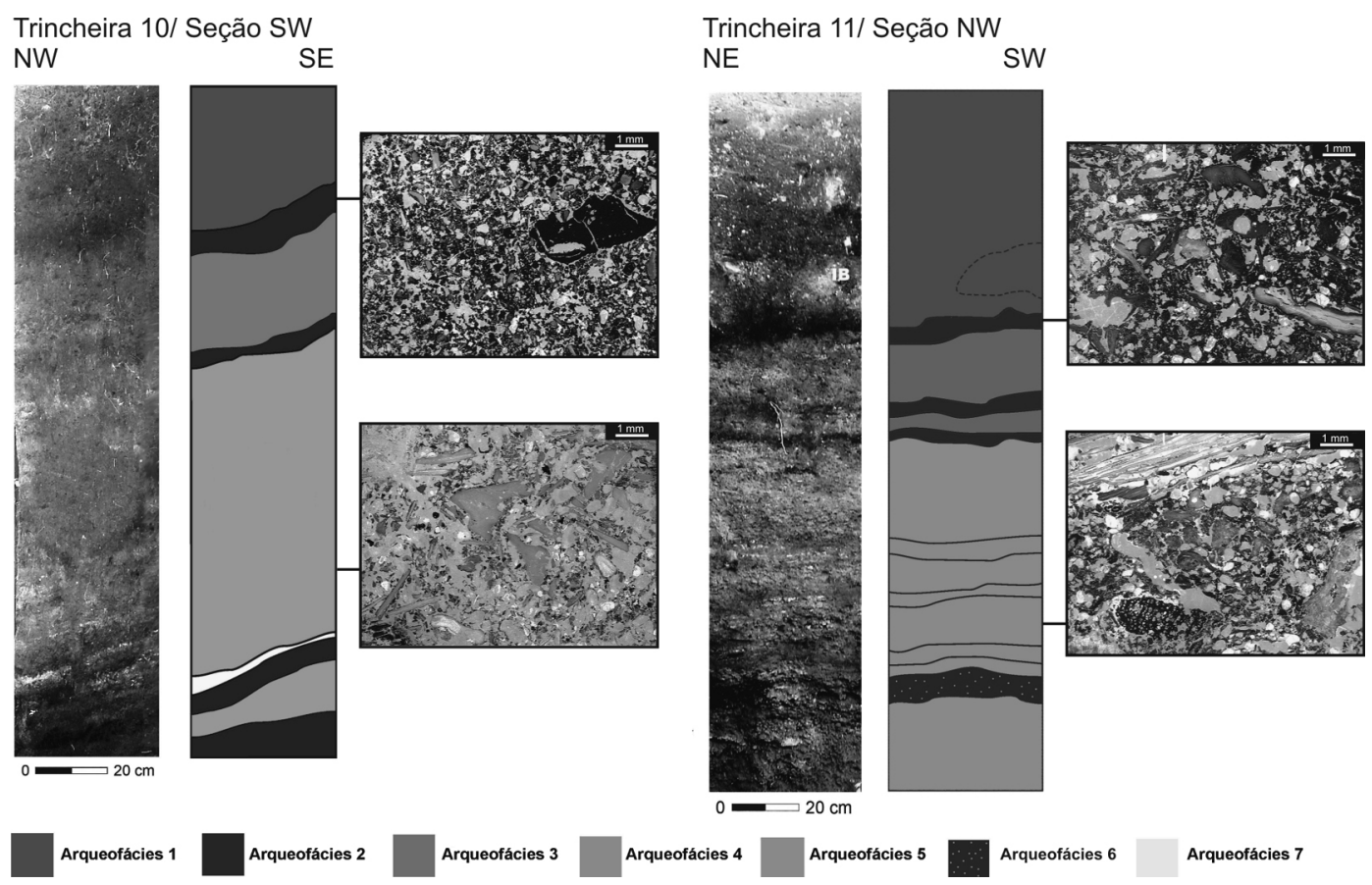

Fig. 3. Seções colunares em Jabuticabeira II, Trincheiras 10 e 11, com arqueofácies identificadas e fotomicrografias correspondentes (PPL). A unidade escura na base da trincheira 11 foi agrupada na arqueofácies 5 , já que possui a mesma composição e arranjo desta fácies, embora tenha sofrido alterações pós-deposicionais advindas de combustão na arqueofácies 6 , acima, que corresponde a uma fogueira in-situ.

determinada por análises granulométricas, que verificaram a correspondência com os depósitos paleolagunares das proximidades do sitio. Isto significa que as areias terrigenas que compõem o depósito não foram trazidas pelo vento, e sim transportadas por agentes antrópicos (Fig. 3). A hipótese de transporte é corroborada pela grande quantidade de diatomáceas, tipicas de ambientes estuarino-lagunares (Paula G.C. Amaral, comunicação pessoal), identificadas em ambas as trincheiras do ictio-montículo. Além desses componentes biogênicos, também se identificou uma série de resíduos silicificados produzidos após a queima de material vegetal, tais como fitólitos fundidos e escória vitrea (frequência de 5-10 \%) (Villagran et al. 2010).

Micro-análises e mapeamento elementar com sistema MEV-EED mostraram que os componentes da fração grossa estão distribuidos aleatoriamente em duas frações finas diferentes, de acordo com a fácies de deposição onde ocorrem: uma de composição fosfática
(Fig. 4B); e outra composta basicamente de micro-carvão (Fig. 4A). A primeira teria sido produzida após a dissolução e re-precipitação da matriz mineral dos ossos, sob a forma de fosfatos de cálcio neo-formados (ver Berna et al. 2004; Lima et al. 2002; Linse 1992; Simpson et al. 1996; Smith et al. 2007; Trueman et al. 2004), também detectados por DRX; ao passo que a segunda adveio da formação e deposição de micro-carvões. Entretanto, ambas são extremamente ricas em silica e parecem estar misturadas com os residuos silicificados da queima e decomposição de material vegetal. Isso significa que, apesar de os fragmentos de ossos serem o componente mais relevante no ictio-monticulo, as plantas - queimadas ou decompostas - também são componentes importantes, embora menos visiveis, do depósito. Merecem destaque as gramineas, cujos fitólitos são comuns e cujas cinzas foram identificadas em grande abundância na base de ambos os perfis estudados. 

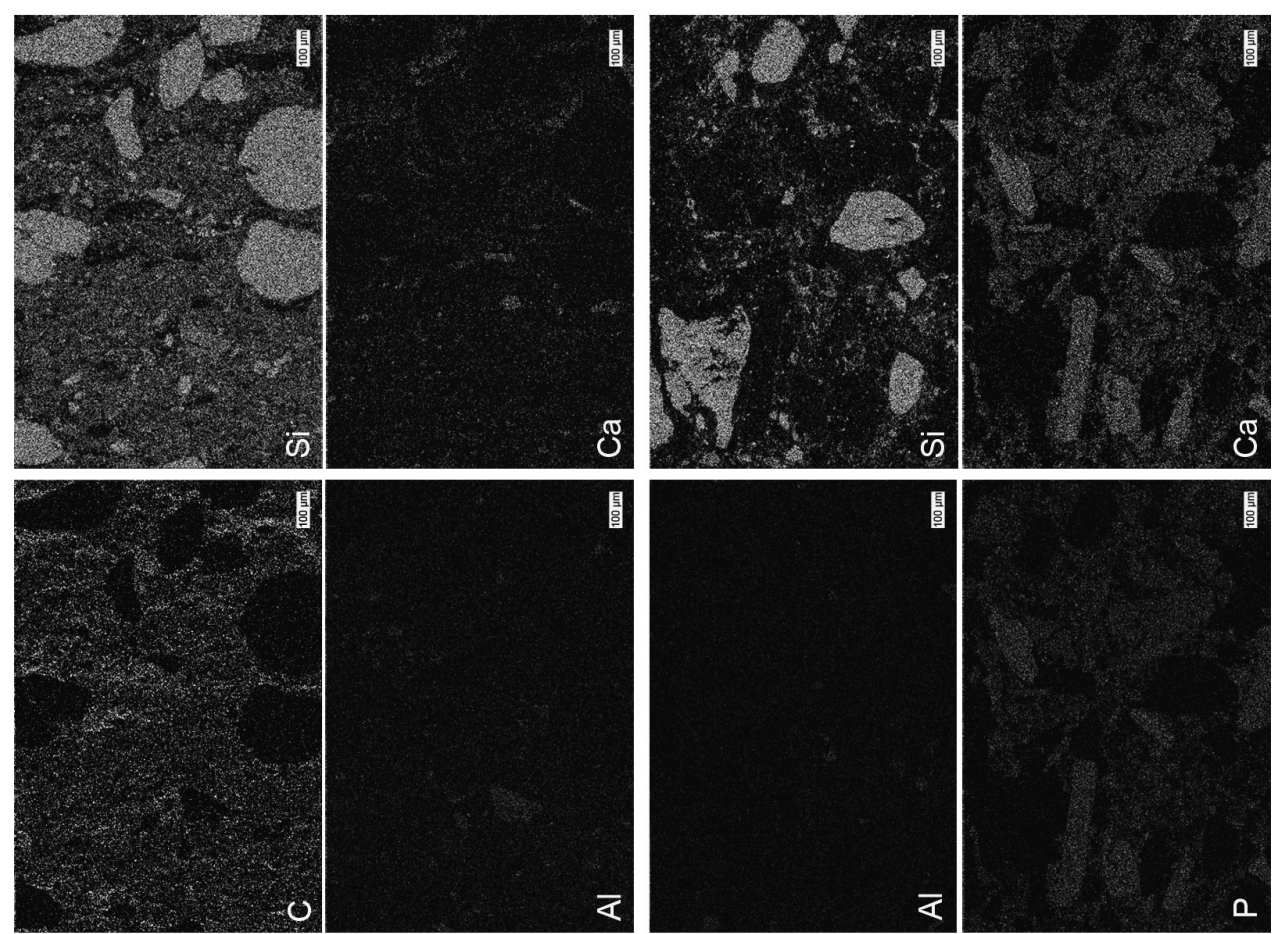

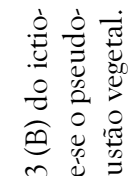

艺艺

$\sim \underset{n}{0}$

:

范 $\cong$

छ.

证
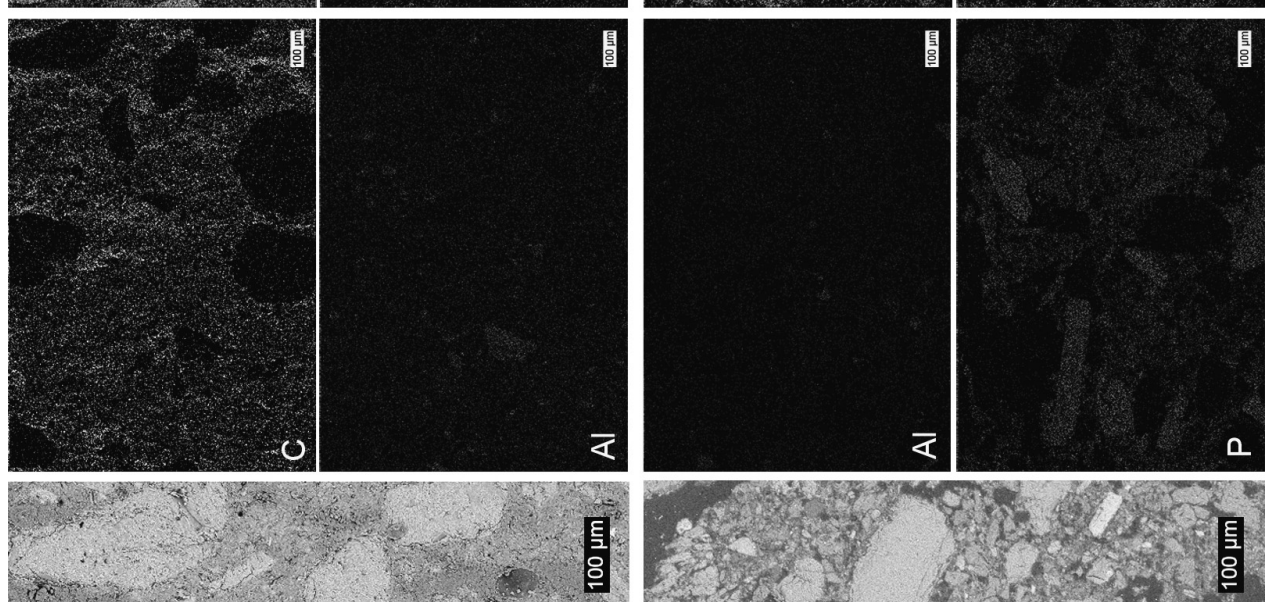

胥

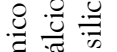

皆

它究

छ) ฮ

을

चे

$\Xi \sim$

胥 .

䓀

के है

奈

कृ $\cong$

苞过

की चै

ส

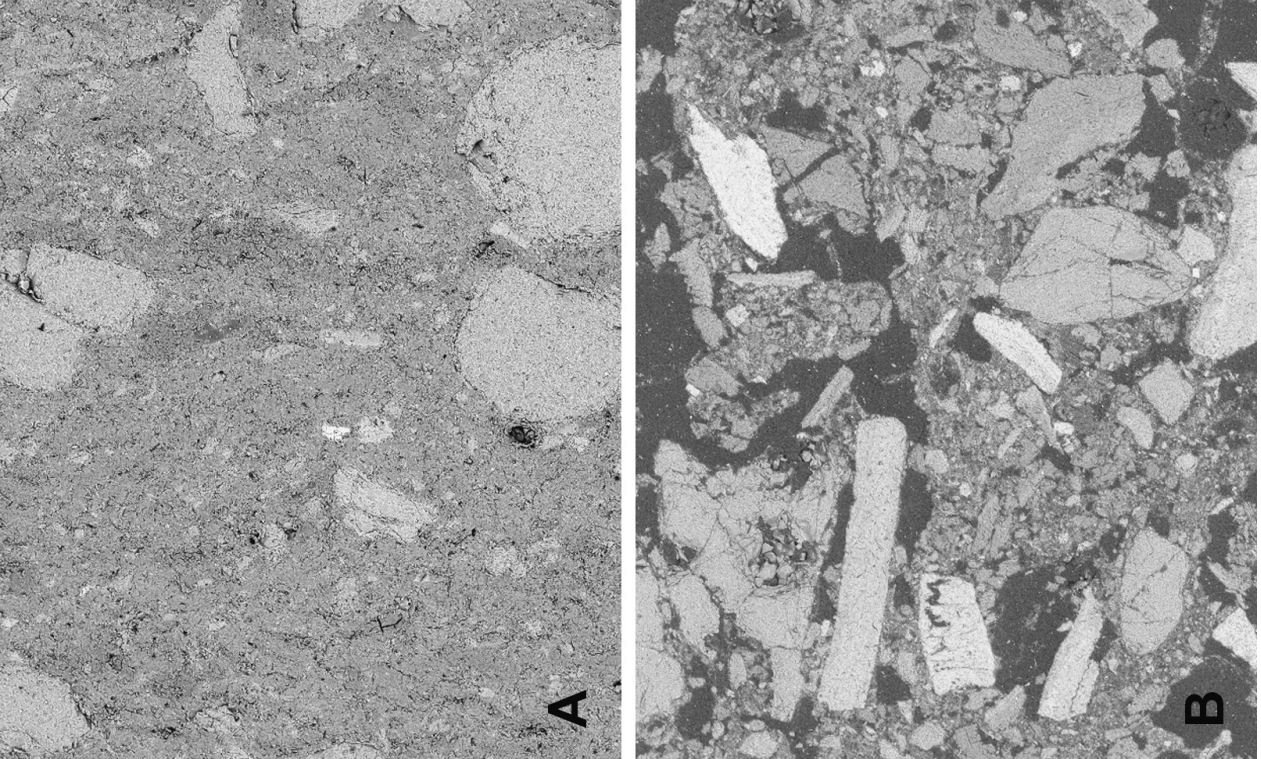

$\Xi \stackrel{0}{3}$

क छ

웡

$\frac{v}{2} \omega^{\circ}$

ษ

5 훙요

¿

管

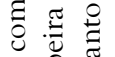

(ี )

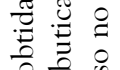

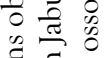

हี

토 올

$\dot{+} \cdot \stackrel{\Xi}{\Xi}$

它 
Os pedo-carateres identificados, texturais e excrementais, indicam que o ictio-montículo foi formado em um periodo de tempo relativamente curto de deposição e não-deposição, em clima úmido, com maior bioturbação na camada superior, mais exposta ao intemperismo (Villagran 2010; Villagran et al. 2010).

A mistura de fragmentos de ossos queimados e alterados que caracteriza o ictio-montículo em escala tanto macroscópica e microscópica, juntamente com as suas propriedades estruturais, tais como a porosidade elevada e a falta de um substrato queimado para cada unidade, sugerem que as particulas não foram queimadas in situ, e sim trazidas ao sítio de outro local (Villagran 2008, 2010; Villagran et al. 2009; Villagran et al. 2010). Esta hipótese de transporte é apoiada pela alta frequência de areias paleolagunares e pela variedade de espécies de diatomáceas estuarinas que compõem o depósito. Isso provavelmente significa que cada camada representa momentos discretos de remobilização de material descartado e termicamente alterado oriundo de fogueiras ou de um depósito secundário de tipo midden. Esse depósito teria estado originalmente situado sobre substrato arenoso, que teria servido de fonte de areia terrigena e diatomáceas, tal como a praia paleolagunar que existiria nas proximidades do sitio quando este foi construido (Giannini 1993; Kneip 2004).

Assim, o ictio-montículo estaria estruturado de acordo com um padrão que intercala fácies decimétricas de ossos alterados com micromassa fosfática e fácies centimétricas de ossos queimados com micro-massa carbonácea. Tal padrão indica uma sequência uniformizada de episódios deposicionais nos quais itens alimentícios descartados e resíduos de fogueira eram usados na construção dos montículos funerários.

Na Fig. 5, apresentam-se a sucessão deposicional da área de localização de Jabuticabeira II e uma reconstrução do seu contexto de localização há aproximadamente 3.000 anos AP. No bloco diagrama superior, observa-se a geometria monticular que conforma o sambaqui e a relação entre depósito antrópico e substrato natural (formado por paleodunas de geração eólica 2, embaixo do sítio, e sedimentos paleolagunares, nas imediações). No bloco diagrama inferior, apresenta-se uma reconstrução hipotética da formação do sítio com localização da área de acumulação e queima de resíduos, sobre uma possivel praia lagunar, da qual teriam provindo os materiais constituintes do ictio-monticulo.

\section{O Sítio Encantada III}

O sitio Encantada III está localizado a aproximadamente $4 \mathrm{~km}$ de Jabuticabeira II e a cerca de $1.200 \mathrm{~m}$ da costa (Fig. 1B). Trata-se de um pequeno sambaqui, de aproximadamente 2 $\mathrm{m}$ de altura (34 $\mathrm{m}$ de comprimento e $15 \mathrm{~m}$ de largura). Apesar do seu volume reduzido, possui datas radiocarbônicas bastante antigas de $4.420 \pm 50 \mathrm{AP}$, em concha (Fish et al. 2000), e $4.320 \pm 40$ anos AP, em carvão (DeBlasis et al. 2007). Uma amostra de carvão coletada no topo do sítio forneceu a data recente de $740 \pm$ 40 anos AP (Scheel-Ybert et al. 2010) que pode ser atribuida a uma ocupação muito posterior, sem relação direta com a construção do sambaqui.

Encantada III é um exemplo de sambaqui que aparece frequentemente como estrutura satélite em torno de sambaquis monumentais, porém, apresentando uma estratigrafia muito mais simples (Peixoto 2008). Este foi o primeiro sítio de pequenas dimensões a ser foco de investigação multidisciplinar na região. Análises faunisticas e paleobotânicas (Scheel-Ybert et al. 2010), além de sedimentares e geofísicas (Rodrigues 2009), foram realizadas no sitio, gerando uma ampla gama de dados para o seu estudo. No caso de Encantada III, as análises geoarqueológicas serão apresentadas antes dos resultados da zooarqueologia. Isto demonstra a maneira em que ambas as abordagens não se subordinam mas se complementam mutuamente.

\section{Geoarqueologia}

A estratigrafia de Encantada III caracterizase por um núcleo arenoso amarelo-claro de até $1,5 \mathrm{~m}$ de altura coberto por uma camada decimétrica areno-argilosa preta rica em material orgânico e conchas, com espessura 


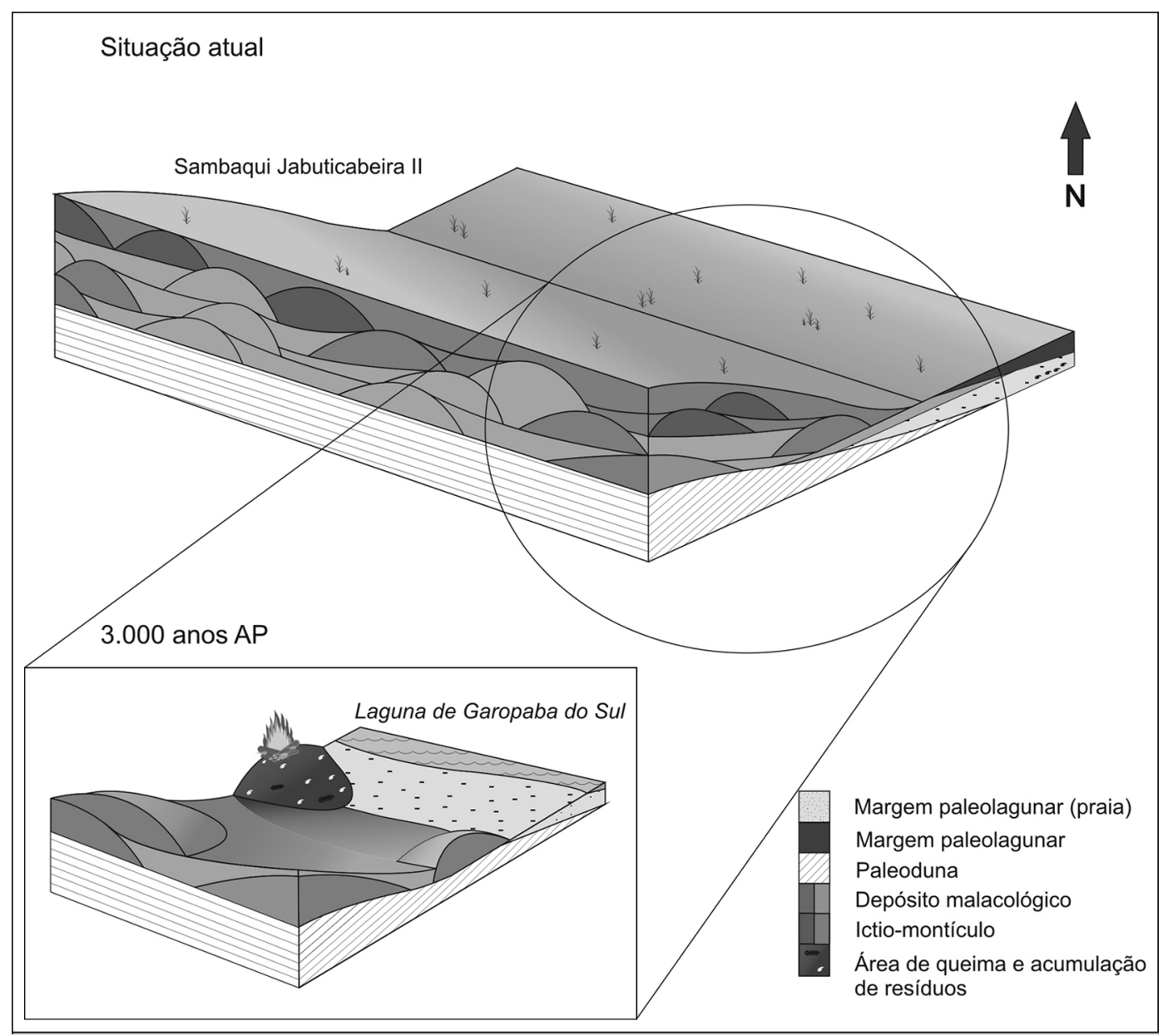

Fig. 5. Modelo de reconstituição da sucessão deposicional atual, e há aproximadamente 3.000 anos, em Jabuticabeira II, baseado na bibliografia (Giannini 1993; Rodrigues 2009) e nas sucessões observadas no sítio e nas sondagens externas.

entre 25 e $40 \mathrm{~cm}$ (Fig. 6A). Essas duas camadas foram identificadas como arqueofácies 1 (núcleo arenoso) e arqueofácies 2 (camada areno-argilosa preta, com conchas ). A arqueofácies 2 possui arcabouço composto principalmente por conchas, exibe escasso conteúdo de ossos de peixes e não contém nenhum sepultamento humano. Estudos paleobotânicos realizados a partir de fragmentos de carvão da arqueofácies 2 revelaram a presença de vegetação de mangue no sítio (Scheel-Ybert et al. 2010).

Para análise geoarqueológica, duas trincheiras foram abertas em etapa de campo realizada em 2006: uma no centro do sítio e outra em seu lado sudeste, que cobre o contato do sambaqui com o substrato natural. A sucessão observada embaixo do sítio, na segunda trincheira, corresponde a uma fácies arenosa amarela sobre uma fácies areno-argilosa preta. As fácies foram interpretadas, com base em descrições e datações radiocarbônicas e por luminescência, como fácies possivelmente marinha, correspondente à barreira arenosa, sobre uma fácies de margem paleolagunar, respectivamente (Fig. 7). Esta sucessão demonstraria o avanço ao interior (transgressão) das areias do sistema barreira por sobre os sedimentos paleolagunares. Assim, o sambaqui teria sido construído na margem retrobarreira da paleolaguna. Amostras de sedimento total 


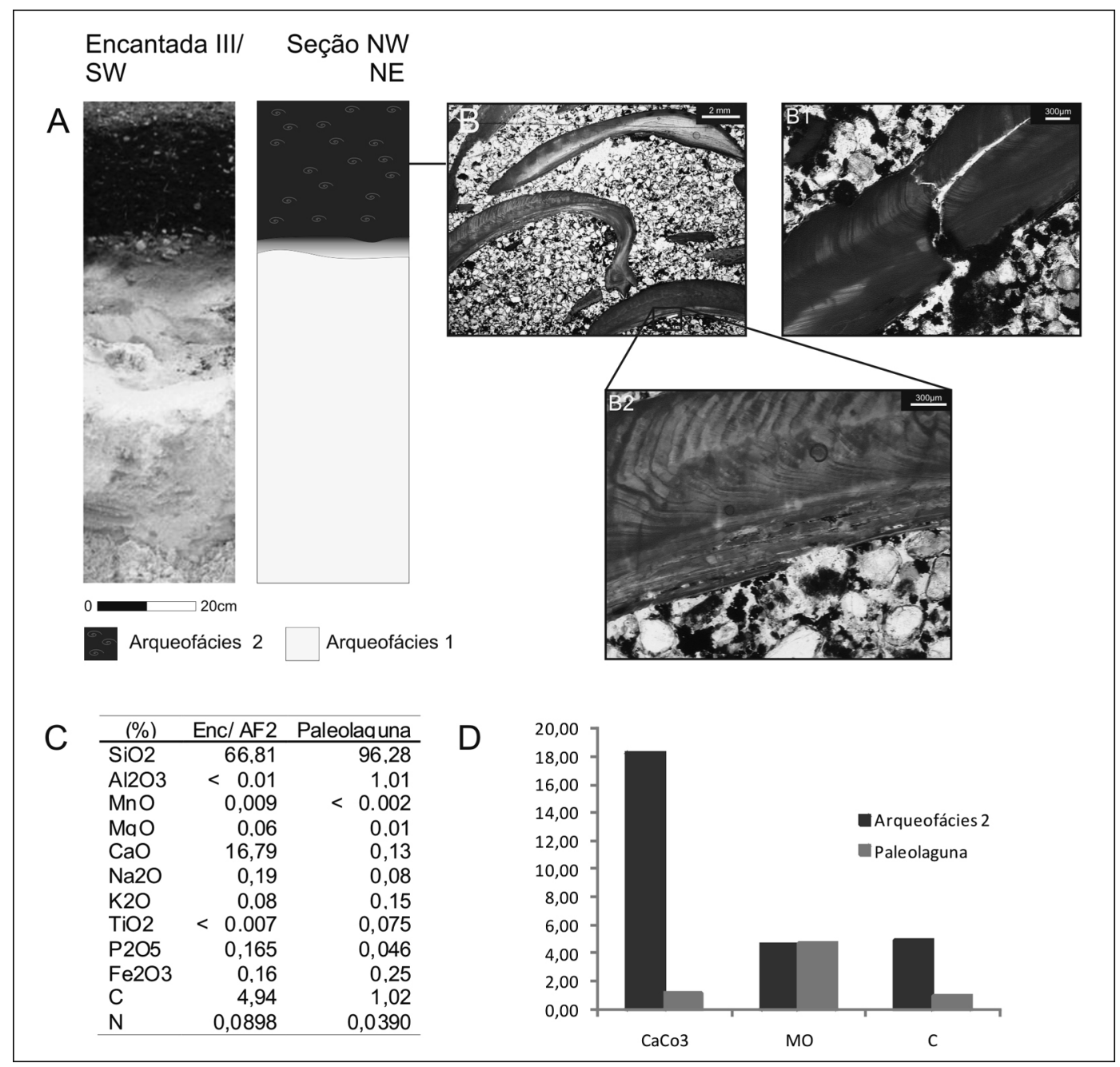

Fig. 6. Análises geoarqueológicas em Encantada III. A) Seção colunar com identificação de arqueofácies. B) Fotomicrografia (PPL) da arqueofácies 2 com conchas na micromassa granulosa, amorfa e preta. B1) Detalhe da quebra in-situ de uma concha. B2) Detalhe de concha com sinais de queima (escurecimento e fissuras longitudinais na sua superfície). C) Composição química multi-elementar da arqueofácies 2 e da fácies de margem paleolagunar. D) Carbonato de cálcio $(\mathrm{CaCo})$, matéria orgânica $(\mathrm{MO})$ e percentuais totais de carbono $(\mathrm{C})$ na arqueofácies 2 e na fácies de margem paleolagunar.

foram extraidas da arqueofácies 2 e da fácies de margem paleolagunar, que serviu como amostra de controle exterior ao sitio. As amostras foram processadas seguindo os mesmos procedimentos descritos para Jabuticabeira II.

Com base no tamanho e orientação do sítio, o seu núcleo arenoso (arqueofácies 1) poderia estar relacionado a uma paleoduna parabólica alongada ou imbrincada, como as que ocorrem na região de localização do sítio, posteriores ao máximo de inundação holocênico (Giannini 1993; Giannini et al. 2007) (Fig. 7). Contudo, nem a forma dômica pronunciada, nem a estrutura interna sem resquícios de estratificação gerada por dinâmica dunar, nem o contexto de localização, isolado, sem associação com outras feições eólicas, permitem vincular este depósito com as dunas eólicas identificadas na região por Giannini (1993), Giannini et al. (2007), Martinho (2004) e 


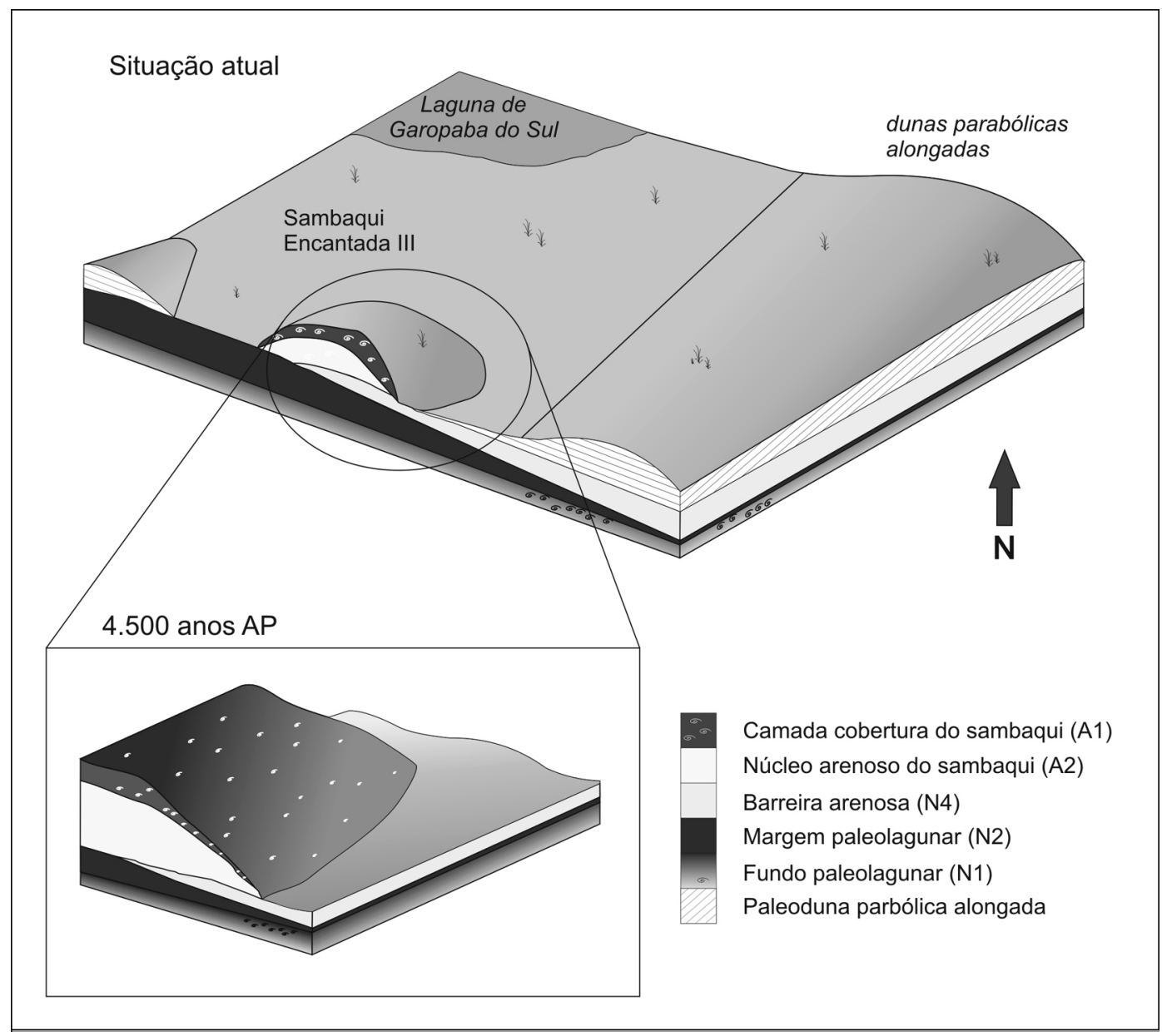

Fig. 7. Modelo de reconstituição da sucessão deposicional atual, e há aproximadamente 4.500 anos, em Encantada III, baseado na sucessão observada na trincheira aberta no lado sudeste do sítio. No diagrama superior, observa-se a localização do sambaqui sobre a barreira arenosa, junto com paleodunas eólicas de geração 3 (pósmáximo de transgressão holocênico). No diagrama inferior, apresenta-se a reconstituição hipotética da situação há 4.500 anos, momento em que o sítio teria alcançado a sua configuração final.

Martinho et al. (2006). Isto levou a considerarse o núcleo arenoso como uma estrutura arqueológica construída. O mesmo tipo de constatação foi realizado no sambaqui Carniça III, localizado na região de Campos Verdes, que, apesar de ultrapassar em pelo menos $2 \mathrm{~m}$ a altura de Encantada III, teve seu núcleo arenoso igualmente associado à deposição antrópica (Tanaka 2007).

As análises granulométricas da fração areia da arqueofácies 2 e da fácies de margem paleolagunar mostraram uma forte proximidade em diâmetro médio, desvio padrão e assimetria. A fração dominante de ambas as fácies é areia média. Análises químicas multielementares mostraram percentuais elevados de cálcio e carbono no sambaqui, relacionados ao carbonato de cálcio das conchas (Fig. 6C). Uma concentração ligeiramente mais elevada de fósforo também foi observada, quatro vezes maior que a concentração da margem paleolagunar, mas ainda baixa se considerada a massa total. Os fosfatos na arqueofácies 2 são definitivamente de origem antrópica, possivelmente relacionados ao conteúdo de ossos de peixe. Além do conteúdo de conchas, a arqueofácies 2 possui 
fortes semelhanças físico-químicas com a fácies de margem paleolagunar, com percentuais quase idênticos de matéria orgânica (Fig. 6 D). Menezes (2009) identificou o mesmo sinal isotópico para a matéria orgânica em ambos os depósitos, o que corrobora esta semelhança. Essa composição similar sugere que materiais do sambaqui podem ter sido retirados de depósitos paleolagunares das redondezas do sitio, uma vez que Encantada III, assim como Jabuticabeira II, também teria estado próximo à margem paleolagunar na época de sua construção.

Em seção delgada, a arqueofácies 2 possui uma micro-estrutura de microagregados intergranulares, e fração grossa composta de conchas (20\%) e grãos de quartzo (40\%), além de micromassa granulosa amorfa e preta (Fig. 6B). A maioria das conchas exibe orientação horizontal a sub-horizontal, não possui perióstraco preservado, e exibe indicios de fratura in situ (Fig. 6B1), além de sinais de queima a temperaturas médias (cerca de $500^{\circ} \mathrm{C}$ ), na forma de fissuras, rachaduras, superfícies ásperas e coloração escura (Fig. 6B2).

Em resumo, análises geoarqueológicas mostraram que a camada conchifera de Encantada III é composta por uma mistura de sedimentos de margem paleolagunar com conchas queimadas e carvão, além de alguns fragmentos de ossos. A ausência de estruturas de combustão e a presença de material queimado indicam que os componentes teriam sido queimados em outro local e transportados para o sitio, ou fortemente trabalhados repetidas vezes sobre o montículo arenoso (arqueofácies 1) após a combustão. Contudo, a segunda hipótese parece menos provável devido à orientação sub-horizontal das valvas de molusco e indícios microscópicos de quebra in situ, o que indica que o retrabalhamento pós-deposicional foi provavelmente baixo.

\section{Zooarqueologia}

As análises zooarqueológicas em Encantada III seguiram o protocolo proposto por SchellYbert et al. (2005-2006). A coleta de amostras foi realizada na camada conchifera (arqueofacies 2) em niveis arbitrários de $10 \mathrm{~cm}$. Tal coleta resultou em quatro amostras de 100 litros cada, que abrangem toda a extensão vertical da camada conchifera do sítio. Após o processamento das amostras para recuperação dos carvões para análises antracológicas, todas as conchas foram descartadas, entretanto decidiu-se utilizar os materiais mesmo sem os moluscos para uma primeira avaliação do conjunto faunístico do sitio. Para complementar as informações da amostragem sem moluscos, utilizou-se uma amostra de aproximadamente 1,5 litro advinda da coleta para análises geoarqueológicas, na qual se incluem todos os componentes.

As quatro amostras de 100 litros analisadas exibem frequências similares das três categorias de animais - peixes, siris e bolachas do mar. A exceção mais notável é o aumento dos restos de peixes na amostra mais inferior $(30-40 \mathrm{~cm})$. Esta última contém quatro vezes a quantidade de ossos contabilizados através do NISP (número de espécimes identificados) encontrada nas outras amostras. Entretanto, devido à alta porosidade da matriz sedimentar, é possivel que tenha havido deslocamento vertical de pequenos ossos de peixes.

Estes resultados confirmam o caráter peculiar do sitio, com altas frequências de bolachas do mar (17\%) e siris (9\%) (Fig. 8A). Os restos de peixes são provenientes, em sua maioria, de pequenos espécimes e encontram-se muito fragmentados, e respondem por $63 \%$ do total de restos, com base no NISP. Assim como em Jabuticabeira II, as espécies de peixe mais comuns são a corvina (40\%) e o bagre (20\%) (Klökler 2006).

Quanto à presença de bolachas do mar, cabe ressaltar que em Jabuticabeira II foram quantificados oito vezes menos fragmentos de bolachas do mar (descontando-se as diferenças de tamanho da amostra) que em Encantada III. Os equinodermos recuperados deste último estão altamente fragmentados, e mais de $85 \%$ exibem sinais de queima (Fig. 8B), uma frequência muito mais alta do que outros componentes faunísticos do sítio. As bolachas do mar não são comestiveis, e a literatura arqueológica até o momento não identifica seu uso como adorno por esses grupos pescadores-coletores, o que sugere que foram transportadas e queimadas 
provavelmente de maneira acidental junto com os moluscos.

É importante mencionar a escassa presença de vertebrados entre as amostras de Encantada III. O sitio tem aproximadamente apenas $2 \%$ do valor do NISP de peixes recuperados de uma camada de conchas de Jabuticabeira II com o número mais baixo de restos de peixes (Fig. 8C). Encantada III assemelha-se mais à porção basal do sítio Espinheiros II - localizado em Joinville, SC - construida para formar uma plataforma (Figuti e Klökler 1996).

$\mathrm{Na}$ amostragem de 1,5 litro, Anomalocardia brasilianaé o molusco mais comum $(87 \%$ a partir do NISP), mesmo padrão verificado em outros sitios de grande porte das redondezas e em proporção similar à encontrada no depósito paleolagunar de Encantada localizado próximo ao sitio. Além de A. brasiliana, foram identificados os seguintes moluscos: Lucina pectinata, Thais haemastoma, Nassarius vibex, e outras diferentes espécies de mariscos e gastrópodes (Tabela 1). As valvas em geral têm indicios de intemperismo, na forma de coloração amarelada na superficie, traços de dissolução e alta fragilidade. Evidências de queima foram obervadas em $40 \%$ das conchas analisadas, como coloração acinzentada nas valvas.

A presença de sedimentos paleolagunares em Encantada III permite cogitar a possibilidade de uma proveniência semelhante para os elementos faunísticos no sítio. Para verificar essa hipótese, amostras de conchas do depósito paleolagunar foram analisadas em relação à composição taxonômica e características tafonômicas, para comparação com o material no sambaqui. Pesagens das valvas demonstram que Anomalocardia brasiliana predomina e tem frequências similares em ambos os depósitos (86\% no depósito paleolagunar, 89\% no sambaqui) (Figura 8D). Gastrópodes, como Thais haemastoma e Nassarius vibex, perfazem 4\% da amostra do sambaqui (versus $2 \%$ no depósito lagunar). Lucinas (Lucina pectinata) apresentam-se em quantidades similares nos dois tipos de depósitos (4\%). A diferença principal refere-

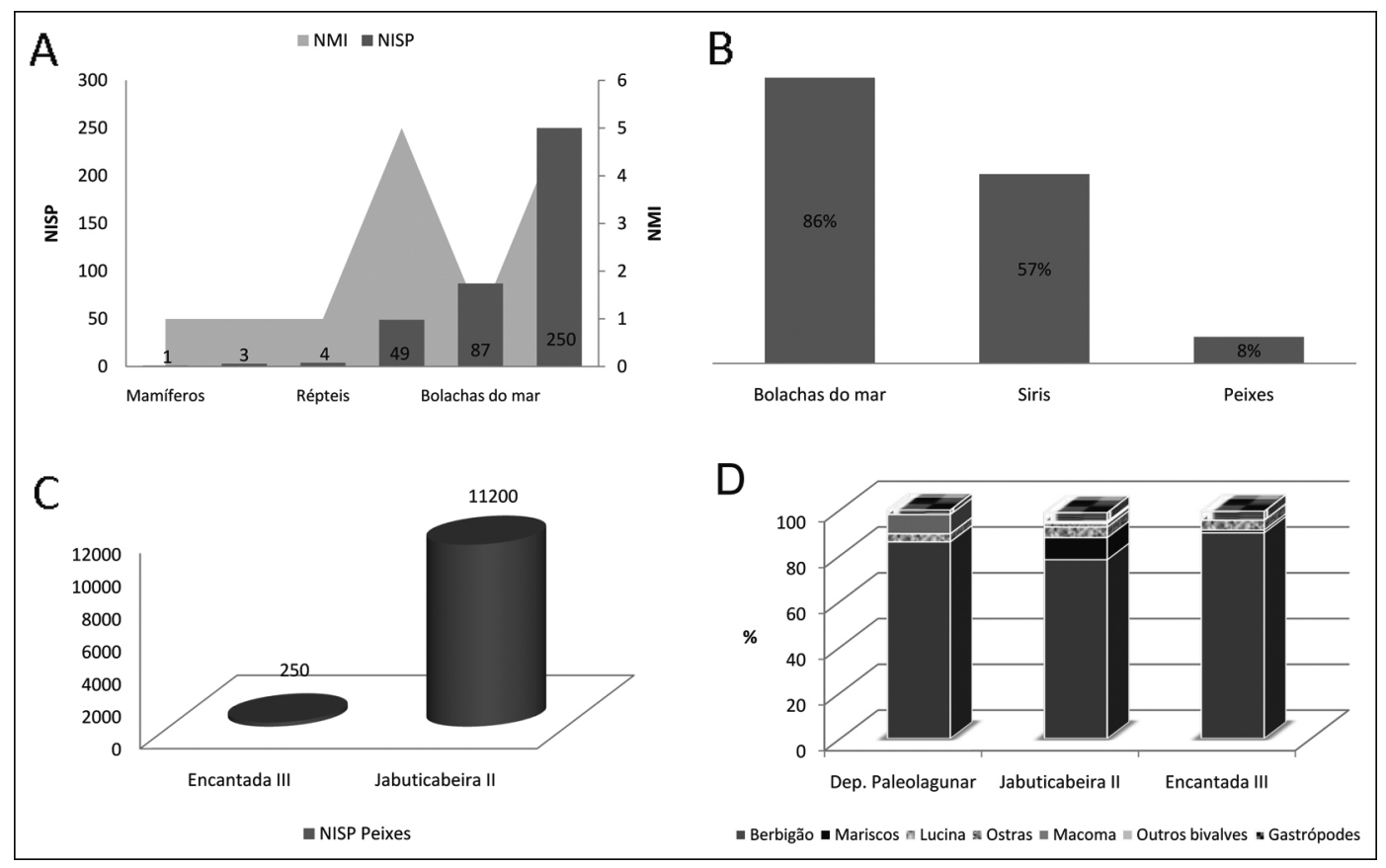

Fig. 8. (A) Número de espécimes identificados (NISP) e número minimo de individuos (NMI) de diferentes taxas recuperados de Encantada III. (B) Frequências de materiais afetados pela queima. (C) Comparação de valores NISP de peixes entre Encantada III - valor NISP de peixes total - e Jabuticabeira II - camada 26; (D) Porcentagem de moluscos em Encantada III, Jabuticabeira II e depósito paleolagunar. 
se à presença de mariscos, especialmente Tagelus sp., em Encantada III (aproximadamente 1\%) e ausência completa de quaisquer mariscos no depósito natural. Mariscos são raramente mencionados em estudos sobre taxa encontrados em depósitos lagunares da região (ver Caruso 1995).

Em geral, as conchas no depósito natural estão melhor preservadas, enquanto no sambaqui apresentam maior friabilidade, sinais de dissolução, manchas amareladas e película de coloração escura nas superfícies interna e externa. Quanto à quantidade de conchas articuladas, até o momento, Encantada III é o sítio com maior presença de berbigões fechados dentre os sambaquis estudados na região.

A camada conchifera de Encantada III poderia ter sido depositada com propósito construtivo, com o intuito de criar um montículo ou plataforma para realização de atividades especificas (Peixoto 2008). No entanto, não há indícios claros do caráter dessa atividade, já que nenhuma estrutura foi identificada dentro ou nas redondezas. Uma outra possibilidade referese ao uso das conchas como elemento que outorga estabilidade ao núcleo arenoso e mantém a sua forma.

A estratigrafia do sitio, bem como as análises zooarqueológicas e geoarqueológicas, indicam sua formação por deposição continua, e não por episódios deposicionais separados no tempo. De fato, este sambaqui parece ter sido construido de maneira rápida, com a deposição de materiais em curtos intervalos de tempo. $\mathrm{O}$ fato de Encantada III estar localizado próximo a sambaquis monumentais ativos à época da construção do sítio (ver mapas em Giannini et al. 2010) chama a atenção para a provável relação entre sambaquis grandes e pequenos. Teria existido um vínculo entre a função de Encantada III e os sitios funerários? Seria possivel admitir seu uso como fonte de materiais que seriam posteriormente depositados nos sambaquis maiores?

A ausência de estruturas e presença de apenas uma lasca em Encantada III (Peixoto 2008) sugere que a ocupação foi de curta duração e que atividades principais não ocorreram no sítio. Muito provavelmente,
Encantada III atuou como marcador territorial, além de servir como espaço para atividades especificas de processamento. Em uma área plana, tal como a planície costeira da região de estudo, até mesmo um pequeno acúmulo de conchas como Encantada III poderia funcionar como um indicador do domínio de um grupo.

\section{Integração das abordagens}

Os processos de formação de sitios conchiferos tem sido alvo de pesquisas desde o início da década de 90 (Stein 1992; Stein et al. 1992). Esses trabalhos foram fundamentais para expandir o conhecimento da multiplicidade de processos culturais e naturais que contribuiram para a formação deste tipo particular de registro arqueológico. Na literatura brasileira, os processos de formação de sambaquis tornaramse foco de pesquisas mais tardiamente. $\mathrm{O}$ trabalho de Klökler e Figuti (1996), ao ir além do estudo da subsistência, foi a primeira tentativa de compreender a formação de um sitio conchifero através do uso da zooarqueologia.

Os estudos geoarqueológicos recentes fornecerem novas técnicas e métodos para analisar e interpretar as estratigrafias de sambaquis, e complementar os resultados das análises faunisticas. Segundo essa perspectiva, os sambaquis - tanto os monumentais como os de pequeno porte - são concebidos como outro produto deposicional dentre os muitos que configuram uma paisagem, porém, o único que resulta da intervenção humana, com seus propósitos e significados particulares. Nesse sentido, tanto as variáveis naturais quanto antrópicas devem ser consideradas na análise e interpretação dos múltiplos agentes e sequência de eventos envolvidos na formação dos sítios.

As análises faunisticas realizadas em Jabuticabeira II enfocaram a compreensão da coleta, utilização e deposição dos restos faunísticos que compõem a matriz. Através do estudo dos dois materiais básicos de construção - peixes e conchas - forneceram-se dados e interpretações acerca da construção do sítio através de sepultamentos episódicos. A deposição de camadas maciças de conchas teria como objetivo cobrir 
covas e grandes áreas funerárias, nas quais eram depositados restos de festins celebrados em homenagem aos mortos. A escolha de valvas de moluscos como material construtivo estaria relacionada, provavelmente, às suas caracteristicas físicas, como espessura, tamanho e coloração. Os dois primeiros elementos garantiram a elevação rápida da estrutura, ao passo que o último enfatizava a distinção entre camadas de sepultamento e de cobertura. As análises geoarqueológicas, por sua vez, descreveram o histórico pré-deposicional e pós-deposicional do sítio e mostraram a sequência complexa de práticas construtivas, que envolveu a reciclagem de material faunístico e vegetal, antes de sua deposição final como matriz dos montículos funerários.

Embora a maioria dos sambaquis tenha sido formada por meio de atividades organizadas, existe uma grande variedade de estratégias de coleta e deposição de conchas que podem ter sido utilizadas pelas populações pré-históricas. O estudo dessas estratégias pode conduzir a um novo exame da formação desses sítios, assim como auxiliar na compreensão dos comportamentos humanos e do sistema social dos construtores de sambaquis.

No caso de Jabuticabeira II, pode-se afirmar que o sítio foi construido por meio da realização de rituais, cuja matéria prima possui uma história que precede o evento final de deposição.. Assim sendo, o estudo da sua formação possibilitou trabalhar com um nivel diferente de informações e assim conectar os grupos às suas crenças. As áreas funerárias teriam sido formadas através de festins, com grandes banquetes que marcavam comemorações em homenagem aos ancestrais. Os restos animais e vegetais que conformam a matéria prima construtiva do sítio, depositada acima dos sepultamentos para outorgar volume à estrutura, passaram por uma sequência de processamentos, vinculadas à queima e acumulação, que definem uma história pré-deposicional mais complexa que o inicialmente imaginado. Esta história envolve a ritualização dos componentes da vida cotidiana dos sambaquieiros (Villagran et al. 2010), e se materializa na configuração final do sambaqui, O sitio Encantada III, por outro lado, foi construido com propósitos menos duradouros. As atividades de processamento de conchas eram executadas sobre uma plataforma antrópica de areia. Estas atividades envolviam a coleta de moluscos da laguna vizinha (juntamente com a sua matriz sedimentar) e a queima de itens faunisticos, com uso de espécies locais de madeira como combustivel (Scheel-Ybert et al. 2009). As atividades em Encantada III não corresponderiam a um local de moradia ou sítio funerário, e sua ocupação - ou sequência de ocupações - teria sido efêmera.

Em ambos os casos, existe uma dinâmica inerente relacionada ao transporte e transformação antrópica de componentes naturais e culturais em um elemento arquitetônico da paisagem (Villagran 2010). No litoral sul catarinense, verificaram-se indícios de uma verdadeira manipulação ou domesticação da planície costeira. Diferentes propósitos e significados estão associados a essas ações, e estes poderiam ser aproximados através da combinação de análises faunisticas e sedimentares em uma abordagem arqueológica integrada capaz de transcender a associação tradicional da fauna com a subsistência e dos sedimentos com processos naturais.

\section{Conclusão}

O projeto multidisciplinar "Sambaquis e Paisagem", que focou seus estudos no litoral sul de Santa Catarina, forneceu grande apoio aos esforços descritos aqui, realizados conjuntamente por zooarqueólogos e geoarqueólogos. Embora, em muitos casos, não se tenha trabalhado com as mesmas amostras, os resultados das análises faunisticas e sedimentares se complementaram. Informações e interpretações semelhantes foram atingidas acerca das atividades que deram origem aos sitios Jabuticabeira II e Encantada III.

Nos últimos anos, análises zooarqueológicas, geoarqueológicas, geofísicas, paleobotânicas, bem como arqueológicas propriamente ditas, foram realizadas na área de estudo as quais forneceram dados para a interpretação da ocupação da costa. No entanto, as pesquisas 
podem alcançar resultados ainda mais profícuos, e as interpretações podem tornar-se mais robustas, quanto mais os pesquisadores de diferentes especialidades trabalhem conjuntamente, e não de maneira isolada, como foi a regra até muito recentemente.

Acredita-se que as abordagens desenvolvidas no sitio Jabuticabeira II podem servir como parâmetro para investigações futuras em outros sambaquis do litoral brasileiro. A associação de métodos analiticos contribuirá para as comparações futuras entre sitios e inclusive na análise intra-sitio. Planejam-se, em um futuro próximo, intervenções no sambaqui Cabeçuda, localizado na mesma região, onde estudos paleobotânicos serão executados em conjunto com as análises descritas neste artigo.

$\mathrm{Na}$ costa sul de Santa Catarina, os sambaquis são componentes ativos de uma paisagem altamente domesticada. As estruturas de grande porte, pela sua dimensão e visibilidade, são elementos ativos no controle dos movimentos dos individuos e suas relações com a paisagem. Por outro lado, as estruturas menores representam os marcos duradouros de práticas de pequena escala, e expressam o vínculo diário das comunidades costeiras com o seu ambiente construido.

\section{Agradecimentos}

Os autores gostariam de agradecer à FAPESP, aos participantes do Projeto de Pesquisa "Sambaquis e Paisagem" (processo 04/ 11038-0), coordenado por Paulo DeBlasis, Paulo Giannini e Maria Dulce Gaspar, e o apoio financeiro da CAPES (processo 1501-020), FAPESP (processos 97/04094-5, 05/573217, 08/51264-0), CNPq (processo 151457/2009. 3), Fundación Carolina e NSF. Gostariamos de agradecer também a Paula Nishida, por permitir o uso dos dados faunísticos de Encantada III, aos membros das equipes que realizaram etapas de campo de arqueologia e geologia em Jabuticabeira II e Encantada III; Isaac Sayeg e equipe dos Laboratórios de Sedimentologia, Petrografia Sedimentar, Microscopia Eletrônica de Varredura, Difratometria de Raios-X e Quimica e ICP-OES do Instituto de Geociências, Universidade de São Paulo.

KLOKLER, D.; VILLAGRÁN, X.S.; GIANNINI, P.C.F.; PEIXOTO, S.; DEBLASIS, P. Together in the coast: zooarchaeology and geoarchaeology analyses of southern Santa Catarina coast sambaquis. Revista do Museu de Arqueologia e Etnologia, São Paulo, 20: 53-75, 2010.

Abstract: This paper explores the contribution that zooarchaeological and geoarchaeological analyses can bring to the study of shell sites depositional history. combined approach is applied for the study of two sites that represent part of the diversity of shell deposits in the southern coast of Santa Catarina State: Jabuticabeira II, a monumental cemetery; and Encantada III, a smaller shell deposit that, besides its apparent simplicity, presents a challenge for the definition of its function. In Encantada III, zoo and geoarchaeology contributed to a better characterization of its role as short-term deposit of long lasting permanence. Both shell sites, and their practical and symbolical attributions, represent examples of the complex dynamics of the anthropic construction of a landscape.

Keywords: Shell middens - Coastal archaeology - Zooarchaeology Geoarchaeology - Micromorphology. 


\section{Referências bibliográficas}

BECK, A.

1972 A Variação do Conteúdo Cultural dos Sambaquis - Litoral de Santa Catarina. Tese de Doutorado. Universidade de São Paulo, São Paulo.

BERNA, F.; MATTHEWS A.; WEINER S.

2004 Solubilities of Bone Mineral from Archaeological Sites: the Recrystallization Window. Journal of Archaeological Science, 31: 867-882.

BIANCHINI, G. F., SCHEEL-YBERT, R.; GASPAR, M.D.

2007 Estaca de Lauraceae em contexto funerário (sitio Jabuticabeira-II, Santa Catarina, Brasil). Revista do Museu de Arqueologia e Etnologia, 17: 223-229

BOYADJIAN, C.H.

2007 Microfósseis contidos no cálculo dentário como evidência do uso de recursos vegetais nos sambaquis de Jabuticabeira II (SC) e Moraes (SP). Dissertação de Mestrado. Universidade de São Paulo, São Paulo.

BULLOCK, P.; NICOLAS FEDOROFF; JONGERIUS,

A.; GEORGES STOOPS; TURSINA, T.; BABEL, U.

1985 Handbook for Soil Thin Section Description.

Waine Research Publications:

Wolverhampton.

CARUSO, F.

1995 Mapa Geológico e de Recursos Minerais do Sudeste de Santa Catarina. Texto Explicativo e Mapa Na Escala 1:100.000. Programa Cartas de Sintese e Estudos de Integração Geológica 1, Departamento Nacional de Produção Mineral, Brasília.

COURTY, M.A.; GOLDBERGA, P.; MACPHAIL, R.

1989 Soils and Micromorphology in Archaeology. Cambridge: Cambridge University Press.

DE PAULA, N; YAMAMOTO, J.K.; TOGNON, A.A.

1991 Seções delgadas de solos: Método de impregnação com resina plástica araldite. Boletim do IGc-USP, 9: 193-196.

DEBLASIS, P.; FISH, S.K.; GASPAR, M.D.; FISH, P.

1998 Some References for the Discussion of Complexity among the Sambaqui Moundbuilders from the Southern Shores of Brazil. Revista de Arqueologia Americana, 15: 75-105

DEBLASIS, P.; KNEIP, A.; SCHEEL-YBERT, R.; GIANNINI P.; GASPAR, M.D.

2007 Sambaquis e Paisagem: Dinâmica Natural e Arqueologia Regional no Litoral Sul do
Brasil. Arqueologia Sudamericanca/

Arqueologia Sul-americana, 3: 29-61.

EMPERAIRE, J.; EMPERAIRE, A.

1956a Algumas nuevas aportaciones sobre los sambaquis del Brasil Meridional. Compas, Número Especial, 31-36.

1956b Les Sambaquis de la côte meridionale du Brésil: compagnes de fouilles (1954-1956). Journal de la Société des Américanistes, 45: $5-163$

FIGUTI, L.

1992 Les sambaquis COSIPA (4200 à 1200 ans BP): étude de la subsistance chez les peuples préhistoriques de pêcheursramasseurs de bivalves de la côte centrale de l'état de São Paulo, Brésil. Tese de Doutorado. Museum National d'Histoire Naturelle, Institut de Paleontologie Humaine, Paris.

1993 O homem pré-histórico, o molusco e o sambaqui: considerações sobre a subsistência dos povos sambaquianos. Revista do Museu de Arqueologia e Etnologia 3: 67-80.

FIGUTI, L.; KLÖKLER, D.

1996 Resultados preliminares dos vestígios zooarqueológicos do sambaqui Espinheiros II (Joinville, SC). Revista do Museu de Arqueologia e Etnologia, 6: 169-187.

FILIPPINI, J.; EGGERS, S.

2005-2006 Distância biológica entre sambaquieiros fluviais (Moraes, vale do Ribeira de Iguape, SP) e construtores de sitios litorâneos (Piaçaguera e Tenório, SP, e Jabuticabeira II, SC). Revista do Museu de Arqueologia e Etnologia 15-16: 165-180.

FISH, S.K., DE BLASIS, P.; GASPAR, M.D.; FISH, P.

2000 Eventos incrementais na construção de sambaquis, litoral sul do estado de Santa Catarina. Revista do Museu de Arqueologia e Etnologia, 10: 69-87

FITZPATRICK, E.A.

1993 Soil Microscopy and Micromorphology. John Wiley, New York.

GARCIA, C.D.; UCHOA, D.P.

1981 Piaçaguera, um sambaqui do litoral do Estado de São Paulo, Brasil. Revista de Préhistória, 2: 11-84.

GASPAR, M.D.

1994/1995Espaço, rito e identidade pré-histórica. Revista de Arqueologia, 8: 221-237.

1998 Considerations of the sambaquis of the Brazilian coast. Antiquity, 72: 592-615. 
2000 Sambaqui: arqueologia do litoral brasileiro. Rio de Janeiro: Jorge Zahar Editor.

GASPAR, M.D., DEBLASIS, P.; FISH, S.; FISH P.

2008 Sambaqui (Shell Mound) Societies of Coastal Brazil. In: Silverman, H.; Isbel, W.I. (Eds.) Handbook of South America Archaeology. New York, Springer: 319-335.

GASPAR, M.D.; KLÖKLER, D.

2003 Evidence of Agricultural Practices in Southern and Southwestern Coast of Brazil. Paper presentation at SAA $68^{\text {th }}$ Annual Meeting in Milwaukee, April.

GIANNINI, P.C.F.

1993 Sistemas deposicionais no quaternário costeiro entre Jaguaruna e Imbituba, SC. Tese de doutorado. Universidade de São Paulo, São Paulo.

GIANNINI, P.C.; SAWAKUCHI, A.O.; MARTINHO, C.T.; TATUMI, S.H.

2007 Eolian depositional episodes controlled by Late Quaternary relative sea level changes on the Laguna-Imbituba coast, South Brazil. Marine Geology, 237: 143-168.

GIANNINI, P.C.F.; VILLAGRAN, X.S.; FORNARI, M.; NASCIMENTO, D.R.; MENEZES, P.M.L.; TANAKA, A.P.B.; ASSUNÇÃO, D.; DEBLASIS, P.; AMARAL, P.G.C.

2010 Interações entre evolução sedimentar e ocupação humana pré-histórica na costa centro-sul de Santa Catarina. Revista do Museu Paraense Emílio Goeldi, Boletim de Ciências Humanas, 5: 105-128.

KARL, R.

2000 The Relative Chronology of Cultural Episodes at the Coastal Sambaqui, Jabuticabeira II, in Santa Catarina, Brazil. Dissertação de Mestrado. Tucson, University of Arizona.

\section{KLÖKLER, D.}

2001 Construindo ou Deixando um Sambaqui? Análise de Sedimentos. Região de Laguna - SC. Dissertação de Mestrado.

2006 What Should I do With These Shells? Depositional History of Three Brazilian Shell Mounds. Paper presentation at the 71st SAA Annual Meeting in Puerto Rico.

2008 Food for Body and Soul: Mortuary Ritual in Shell Mounds (Laguna - Brazil). Tese de doutorado. Tucson, University of Arizona.

KNEIP, A.

2004 O povo da lagoa: uso do SIG para modelamento e simulação na área arqueológica do Camacho. Tese de doutorado. Universidade de São Paulo, São Paulo.

LIMA, T.A.

1991 Dos Mariscos aos Peixes: um Estudo Zooarqueológico da Mudança de Subsistência na Pré-História do Rio de Janeiro. Tese de doutorado. Universidade de São Paulo, São Paulo.

LIMA, H.N.; SCHAEFER, C.E.R.; MELLO, J.W.V.; GILKES, R.J.; KER, J.C.

2002 Pedogenesis and Pre-Columbian Land Use of "Terra Preta Anthrosolos" ("Indian Black Earth") of Western Amazonia. Geoderma, 110: 1-17.

LINSE, A.R.

1992 Is Bone Safe in a Shell Midden? In: Stein, J. (Ed.) Deciphering a Shell Midden. San Diego, Academic Press: 327-346.

MARTINHO, C.T.

2004 Morfodinâmica e Sedimentologia de Campos de Dunas Transgressivos da Região de Jaguaruna-Imbituba, Santa Catarina. Dissertação de mestrado, Instituto de Geociências, Universidade de São Paulo, São Paulo.

MARTINHO, C.T.; GIANNINI, P.C.F.; SAWAKUCHI, A.O.; HESP, P.A.

2006 Morphological and depositional facies of transgressive dunefields in the ImbitubaJaguaruna region, Santa Catarina State, Southern Brazil. Journal of Coastal Research, Brasil, 39: 673-677.

MEEHAN, B.

1982 Shell Bed to Shell Midden. Australian Institute of Aboriginal Studies, Canberra.

MENEZES, P.M.L.

2009 Análise de fácies e proveniência sedimentar em sambaquis do litoral centro-sul de Santa Catarina. Dissertação de Mestrado. Universidade de São Paulo, São Paulo.

NISHIDA, P.

2007 A coisa ficou preta: estudo do processo de formação da terra preta do sítio arqueológico Jabuticabeira II. Tese de doutorado. Universidade de São Paulo, São Paulo.

OKUMURA, M.; EGGERS, S.

2005 The People of Jabuticabeira II: Reconstruction of the Way of Life in a Brazilian Shellmound. Homo, 55: 263-281.

PEIXOTO, S.A.

2008 Pequenos aos montes: uma análise dos processos de formação dos sambaquis de pequeno porte do litoral sul de Santa 
Catarina. Dissertação de Mestrado. Universidade Federal do Rio de Janeiro, Rio de Janeiro.

RODRIGUES, S.I.

2009 Contribuições dos métodos GPR e eletromagnético indutivo em estudos de sítios arqueológicos de sambaquis costeiros no Estado de Santa Catarina. Tese de Doutorado. Universidade de São Paulo, São Paulo.

SCHEEL-YBERT, R., BIANCHINI, G.F.; DEBLASIS, P.

2009 Registro de mangue em um sambaqui de pequeno porte do litoral sul de Santa Catarina, Brasil, a cerca de 4900 anos cal BP, e considerações sobre o processo de ocupação do sítio Encantada III. Revista do Museu de Arqueologia e Etnologia, 19: 103-118. Scheel-Ybert, R., Eggers, S.; Wesolowski, V.; Petronilho, C.; Boyadjian, C.; DeBlasis, P.; Guimarães, M.; Gaspar, M.D.

2003 Novas perspectivas na reconstituição do modo de vida dos sambaquieiros uma abordagem multidisciplinar. Revista do Museu de Arqueologia e Etnologia, 16: 109-137.

SCHEEL-YBERT, R.,; KLÖKLER, D.; GASPAR, M.D.; FIGUTI, L.

2005-2006 Proposta de amostragem padronizada para macro-vestigios bioarqueológicos: antracologia, arqueobotânica, zooarqueologia. Revista do Museu de Arqueologia e Etnologia, 15-16: 139-163.

SCHIEGL, S., GOLDBERG, P.; PFRETZSCHNER, H.U.; CONARD, N.

2003 Paleolithic burnt bone horizons from the Swabian Jura: distinguishing between in situ fireplaces and dumping áreas. Geoarcheology, 18: 541-565.

SCHOENINGER, M.J., MOORE, K.M.; MURRAY, M.L.; KINGSTON, J.D.

1989 Detection of Bone Preservation in Archaeological and Fossil Samples. Applied geochemistry, 4: 273-280.

SIMPSON, I.; BARRET, J.H.

1996 Interpretation of Midden Formation Processes at Robert's Haven, Caithness, Scotland using Thin Section Micromorphology. Journal of Archaeological Science, 23: 543-556.

SMITH, C.I., NIELSEM-MARSH, C.M.; JANS, M.M.; COLLINS, M.J.

2007 Bone Diagenesis in the European Holocene
I: Patterns and Mechanisms. Journal of Archaeological Science, 34: 1485-1493.

STEIN, J. (Ed.)

1992 Deciphering a Shell Midden. San Diego: Academic Press.

STEIN, J.; KORNBACHER, K.D.; TYLER, J.L.

1992 British camp shell midden stratigraphy. In: Stein, J. (Ed.) Deciphering a shell midden. San Diego, Academic Press: 95-134.

STORTO, C.; EGGERS, S.; LAHR, M.

1999 Estudo preliminar das paleopatologias da população do Sambaqui Jabuticabeira II, Jaguaruna, SC. Revista do Museu de Arqueologia e Etnologia, 9: 61-71.

STOOPS, G.

2003 Guidelines for Analysis and Description of Soil and Regolith Thin Sections. Soil Science Society of America, Madison.

TANAKA, A.P.B.

2007 Evolução Sedimentar da Planície Retrobarreira de Campos Verdes (Laguna, SC) e os Sambaquis de Carniça. Universidade de São Paulo, São Paulo.

TRUEMAN, C.N.G.; BEHRENSMEYER, A.K.; TUROSS, N.; WEINER, S.

2004 Mineralogical and Compositional Changes in Bones exposed in Soil Surfaces in Amboseli National Park, Kenya: Diagenetic Mechanisms and the Role of Sediment Pore Fluids. Journal of Archaeological Science, 31: 721-739.

VILLAGRÁN, X.S.

2008 Análise de Arqueofácies na Camada Preta do Sambaqui Jabuticabeira II. Dissertação de Mestrado. Universidade de São Paulo, São Paulo.

2010 Estratigrafias que falam: geoarqueologia de um sambaqui monumental. São Paulo: Annablume Editora (no prelo).

VILLAGRAN, X.S.; GIANNINI, P.; DEBLASIS, P.

2009 Archaeofacies analyses: using depositional attributes to identify anthropic processes of deposition in a monumental Shell mound of Santa Catarina State (Southern Brazil). Geoarchaeology, 24: 311-335.

VILLAGRAN, X.S.; KLÖKLER, D.; NISHIDA, P.; GASPAR, M.D.; DEBLASIS, P.

2010 Lecturas estratigráficas: Arquitectura funeraria e depositación de residuos en el sambaquí Jabuticabeira II. Latin American Antiquity (no prelo). 